\title{
Magnetite-Functionalized Horse Dung Humic Acid (HDHA) for the Uptake of Toxic Lead(II) from Artificial Wastewater
}

\author{
Rahmat Basuki, Bambang Rusdiarso $\mathbb{D}$, Sri Juari Santosa, and Dwi Siswanta \\ Department of Chemistry, Universitas Gadjah Mada, Yogyakarta 55281, Indonesia \\ Correspondence should be addressed to Bambang Rusdiarso; brusdi_mipa@ugm.ac.id
}

Received 29 January 2021; Revised 16 April 2021; Accepted 26 April 2021; Published 24 May 2021

Academic Editor: George Kyzas

Copyright (C) 2021 Rahmat Basuki et al. This is an open access article distributed under the Creative Commons Attribution License, which permits unrestricted use, distribution, and reproduction in any medium, provided the original work is properly cited.

\begin{abstract}
Magnetite-functionalized horse dung humic acid (HDHA) has been successfully prepared by the coprecipitation method, and the as-prepared adsorbent (MHDHA) has been applied as an easy-handling adsorbent for toxic $\mathrm{Pb}(\mathrm{II})$ in artificial wastewater. The MHDHA was characterized by Fourier transform-infrared spectroscopy (FT-IR), X-ray powder diffraction (XRD), transmission electron microscopy (TEM), energy dispersive X-ray (EDX), and vibrating sample magnetometer (VSM). The FT-IR study showed that the MHDHA had the characteristics peaks of HA and Fe-O stretching. The XRD analysis revealed that the MHDHA had the $2 \theta$ characteristic for magnetite. The TEM image and EDX analysis exhibited that the MHDHA with an average size of $\sim 14 \mathrm{~nm}$ was partially aggregated and contained $(w / w) 9.89 \%$ carbon, $2.89 \%$ nitrogen, and $32.74 \%$ oxygen based on functional groups of HDHA. The stability improvement of MHDHA was showed by decreasing HDHA dissolved from $95 \%$ to less than $30 \%$ at $\mathrm{pH} 12$ after magnetite functionalization. The post-adsorption handling improvement was evidenced by easy and quick retraction by an external magnet with a $62.95 \mathrm{emu} / \mathrm{g}$ magnetic strength value. The adsorption capacities were influenced by the $\mathrm{pH}$ and ionic strength, whilst the adsorption rates were well simulated by the Ho pseudo-second-order model. The removal uptake of $\mathrm{Pb}(\mathrm{II})$ ions increased when the initial concentration was increased and fitted well with the Langmuir isotherm model when the monolayer adsorption capacity was $2.78 \times 10^{-4} \mathrm{~mol} / \mathrm{g}$ (equal to $57.64 \mathrm{mg} / \mathrm{g}$ ). The value of DubininRadushkevich adsorption energy $\left(E_{D-R}\right)$ found in this study was $14.78 \mathrm{~kJ} / \mathrm{mol}$, which implied that ion exchange is the main mechanism involved in the adsorption process. The regeneration studies of MHDHA show that there was no significant change in composition, morphology, crystallinity, and functional group after five consecutive cycles of the adsorption-desorption process.
\end{abstract}

\section{Introduction}

The immoderate release of contaminants into the aquatic environment is a primary global concern. Heavy metal contaminants are a severe threat to the life and development of humankind [1]. Lead is among the most hazardous pollutants that can cause health issues in human beings because it exhibits high toxicity and potential mutagenic and carcinogenic effects [2]. Therefore, the elimination of such contaminants from water has attracted growing attention. Several methods have been developed such as adsorption, organic treatment, photocatalyst, coagulation, ion exchange, membrane separation, solvent extraction, evaporative recovery, reverse osmosis, and chemical precipitation [3,4]. However, though membrane separation is highly efficient, it has low economic viability and high maintenance price for largescale applications. Precipitation and organic treatment are cost affordable, but they cannot reduce the pollutant below the desirable limit and produce a high amount of sludge. Photocatalysis commonly faces photoetching issues and quick electron-hole pair recombination and aggregation catalyst ion problems [5]. Although the adsorption technology has the disadvantages of difficulties in treating and parsing the posttreatment waste, adsorption is amongst the broadly applied technology in water and wastewater remediation. This technology has been identified as the promising, efficient, and extensively used fundamental method in the wastewater remedy processes, specifically hinging on its simplicity, economic viability, technical feasibility, environmental safety, and social acceptance $[3,5]$. 
Numerous candidates of heavy metal adsorbents have been reported to accommodate the properties mentioned above, i.e., fly ash-zeolite to adsorb $\mathrm{Cu}(\mathrm{II}), \mathrm{Fe}(\mathrm{III}), \mathrm{Mn}(\mathrm{II})$, and $\mathrm{Zn}(\mathrm{II})$ [6]; green biowaste as $\mathrm{Pb}(\mathrm{II})$ and $\mathrm{Cd}(\mathrm{II})$ adsorbents [7]; modified activated carbon (AC) for Cd(II) removal [8]; and modified humic acid (HA) for various heavy metal removal [9-18]. HA seems a promising candidate because it is cheap and highly available and has a high adsorption rate and capacity [19]. HA is reported to possibly bind with various toxic metals, organic compounds, and radionuclides because it has an abundant reactive site dominated by carboxylic and phenolic groups [20]. However, utilizing original HA for adsorbent was time-consuming and a costly process because it needs centrifugation or filtration step from water post adsorption [21]. Besides, at $\mathrm{pH}>5$, the original HA begins to dissolve in water. Therefore, the magnetite composite adsorbents have become a desirable material for separating the loaded pollutant. So, magnetite functionalized HA was started to investigate as adsorbents for removing different toxic ions in an aqueous solution. Some of these studies are adsorption for $\mathrm{Cu}(\mathrm{II}), \mathrm{Cd}(\mathrm{II}), \mathrm{Pb}(\mathrm{II})$, and $\mathrm{Hg}(\mathrm{II})$ [10]; Rhodamine B dyes [12]; methylene blue dyes [13, 14]; reductive $\mathrm{Cr}(\mathrm{VI})$ [15]; phenol [16]; $\mathrm{As}(\mathrm{V})$ [17]; and carbamazepine degradation [18]. Magnetite-functionalized HA has also claimed to have better stability and higher adsorption capacity and eliminates additional steps to recover the adsorbent after the adsorption process [10,12-18].

Unfortunately, the functionalized HA in the reported study derives from peat soils [10,12-18]. Whereas peat soil is not a renewable source for HA because its formation takes a long time and peat soil exploration leads to the release of greenhouse gases from stored carbon in peat [22-28], alternatively, much organic biomass considered as waste, such as chicken manure [29], organic biomass [30-33], cow dung $[34,35]$, and horse dung [36-38], is recently reported as a source of renewable HA. Organic waste biomass is commonly used as fertilizer, except for horse dung, due to its rough texture and dense properties [39]. In addition, the existence of horse dung has a lousy effect on the environment because it is often scattered, creates a rotten smell, and is responsible for the appearance of nuisance animals [40]. The utilization of organic waste biomass, particularly horse dung as a renewable HA source, will overcome environmental problems caused by organic waste biomass and sustain the contaminant handling through the adsorption process.

Previous work on horse dung humic acid (HDHA) showed that the material has good removal uptake towards toxic heavy metal pollutants in water [36-38]. Therefore, it is fair to conduct further studies on the material. To our best knowledge, the incorporation of HDHA is still scarce. Hence, the purpose of the present study was to develop functionalized HDHA with enhanced stability, handling, and removal uptake towards toxic $\mathrm{Pb}$ (II) from artificial wastewater. In this study, the HDHA was incorporated with magnetite to produce magnetite-functionalized HDHA (MHDHA). Functionalization magnetite by peat soil HA has proven to enhance the adsorption handling, stability, and capacity; however, no document was found that investigated this for HA from the biological matrix as HDHA.

\section{Materials and Methods}

2.1. Chemicals. All chemicals, $\mathrm{NaOH}, \mathrm{HCl}, \mathrm{HF}$, $\mathrm{Pb}\left(\mathrm{CH}_{3} \mathrm{COO}\right)_{2}, \mathrm{FeCl}_{3} \cdot 6 \mathrm{H}_{2} \mathrm{O}, \mathrm{FeSO}_{4} \cdot 7 \mathrm{H}_{2} \mathrm{O}, \mathrm{NH}_{3}, \mathrm{Ba}(\mathrm{OH})_{2}$, and $\mathrm{Ca}\left(\mathrm{CH}_{3} \mathrm{COO}\right)_{2}$, were of analytical grade produced by Merck ${ }^{\circledR}$ without further purification.

2.2. Adsorbent Preparations. Horse dung humic acid (HDHA) was extracted from 1 to 3 months of age of 50 mesh dry horse dung powder by the alkaline method [41] in the ambient atmosphere. Half a kilogram of dry horse dung powder was soaked into $5 \mathrm{~L} \mathrm{NaOH} 0.1 \mathrm{M}$, and the mixture was stirred for $24 \mathrm{~h}$. The filtrate of the mixture was separated by $3000 \mathrm{rpm}$ centrifugation for $10 \mathrm{~min}$. The filtrate was slowly added with $\mathrm{HCl} 0.1 \mathrm{M}$ until the $\mathrm{pH}$ is approximately 1.0 and aged for $12 \mathrm{~h}$ to form two layers. Crude HDHA (solid layer) was separated by centrifugation at $5000 \mathrm{rpm}$ for $15 \mathrm{~min}$ and dried at $50^{\circ} \mathrm{C}$. The purification of crude HDHA was performed by soaking $10 \mathrm{~g}$ of dry crude HDHA powder into a $200 \mathrm{~mL}$ solution of $0.1 \mathrm{M} \mathrm{HCl} / 0.1 \mathrm{M} \mathrm{HF}(1: 3)$ in a polyethylene flask. The suspension was stirred for $24 \mathrm{~h}$, and the solids were separated by centrifugation at $5000 \mathrm{rpm}$ for $15 \mathrm{~min}$ as purified HDHA. Similar procedures were also applied for the extraction and purification of HA from Sumatra's peat soils as a comparison to HDHA.

The synthesis of magnetite-functionalized HDHA (MHDHA) was conducted by a coprecipitation procedure based on Liu et al. [10] by dissolving $3.05 \mathrm{~g} \mathrm{FeCl}_{3} \cdot 6 \mathrm{H}_{2} \mathrm{O}$ and $2.10 \mathrm{~g} \mathrm{FeSO}_{4} \cdot 7 \mathrm{H}_{2} \mathrm{O}$ into $25 \mathrm{~mL}$ distilled water and heated up to $90^{\circ} \mathrm{C}$. Two solutions, $5 \mathrm{~mL} \mathrm{NH} \mathrm{NH}_{3} 25 \%$ and $0.25 \mathrm{~g}$ purified HDHA, were dissolved in $50 \mathrm{~mL}$ of $\mathrm{NaOH} 0.1 \mathrm{M}$, which were added sequentially and rapidly. The mixture was stirred at $90^{\circ} \mathrm{C}$ for $1 \mathrm{~h}$ and then cooled to room temperature. After $24 \mathrm{~h}$, the black solids of MHDHA were rinsed with distilled water to neutral $\mathrm{pH}$ and dried in a vacuum oven at $50^{\circ} \mathrm{C}$. Also, the bare magnetite was prepared similarly without HDHA addition.

2.3. Characterizations. Characterizations of extracted HDHA were conducted by UV-Vis spectroscopy (Shimadzu UV1700 PharmaSpec) to analyze the humification degree, the functional group analysis by FT-IR (Shimadzu Prestige 21), and the total acidity. The total acidity (sum of carboxylic and phenolic contents) of HDHA was determined by the baryta indirect potentiometric titration method [41] by dissolving $50 \mathrm{mg}$ of the sample into $20 \mathrm{~mL} \mathrm{Ba}(\mathrm{OH})_{2} 0.1 \mathrm{M}$. The suspension was shaken for $24 \mathrm{~h}$. The filtrate was then separated from the solid titrated with standard $\mathrm{HCl} 0.5 \mathrm{M}$ until the $\mathrm{pH}$ reached $8.4\left(V_{s}\right)$. Simultaneously, the titration was also performed to a solution only containing $20 \mathrm{~mL} \mathrm{Ba}(\mathrm{OH})_{2}$ as blank $\left(V_{b}\right)$. The total acidity $(\mathrm{cmol} / \mathrm{kg})$ was determined by $\left[\left(V_{b}-V_{s}\right) \times N \times 10^{5}\right] / w$, where $V_{s}$ and $V_{b}$ were the sample and the blank titration volume $(\mathrm{mL})$, respectively; $N$ was the normality of $\mathrm{HCl}$, and $w$ was the weight of the adsorbent (mg). The carboxylic contents of HDHA were determined by dissolving $50 \mathrm{mg}$ of the sample into $10 \mathrm{~mL}$ of $\mathrm{Ca}\left(\mathrm{CH}_{3} \mathrm{COO}\right)_{2}$ $0.5 \mathrm{M}$ and $40 \mathrm{~mL}$ distilled water. The suspension was shaken for $24 \mathrm{~h}$, and then, the filtrate was separated from the solid titrated with standard $\mathrm{NaOH} 0.1 \mathrm{M}$ until the $\mathrm{pH}$ reached 
$9.8\left(V_{s}\right)$. Simultaneously, the titration was also performed to a solution only containing $10 \mathrm{~mL}$ of $\mathrm{Ca}\left(\mathrm{CH}_{3} \mathrm{COO}\right)_{2} 0.5 \mathrm{M}$ and $40 \mathrm{~mL}$ distilled water as blank $\left(V_{b}\right)$. The total acidity $(\mathrm{cmol} / \mathrm{kg})$ was determined by $\left[\left(V_{s}-V_{b}\right) \times N \times 10^{5}\right] / w$, where $V_{s}$ and $V_{b}$ were the samples and blank titration volume (mL), respectively and $N$ was the normality of $\mathrm{NaOH}$.

The functional group analysis and crystal analysis of MHDHA were performed by FT-IR and XRD (Shimadzu $\mathrm{XRD}-6000)$ using $\mathrm{Cu} \mathrm{K} \alpha$ radiation in the $2 \theta$ range of $10^{\circ}-$ $70^{\circ}$ with a scanning step length of $0.02^{\circ}$. The investigation of the size distribution, elemental analysis, and magnetic properties was conducted using TEM (JEOL JEM-1400), EDX (JSM-6510LA), and VSM (Oxford 1.2H magnetometer), respectively. In addition, the $\mathrm{pH}$ point of zero charged $\left(\mathrm{pH}_{\mathrm{pzc}}\right)$ and stability of MHDHA in different $\mathrm{pH}$ were also evaluated with the following procedure: the $\mathrm{pH}_{\mathrm{pzc}}$ of the MHDHA was determined by the solid addition method [42]. To a series of $50 \mathrm{~mL}$ conical flasks, $25 \mathrm{~mL}$ solution with various initial $\mathrm{pH}\left(\mathrm{pH}_{\mathrm{i}}\right)$ from 2.0 to 12.0 was transferred. $\mathrm{pH}_{\mathrm{i}}$ of the solution was adjusted by adding $0.1 \mathrm{~mol} / \mathrm{L} \mathrm{HNO}_{3}$ or $0.1 \mathrm{~mol} / \mathrm{L} \mathrm{NaOH}$. About $20.0 \mathrm{mg}$ of MHDHA was added to each flask and the mixture was agitated at $150 \mathrm{rpm}$. After $48 \mathrm{~h}$, the final $\mathrm{pH}\left(\mathrm{pH}_{\mathrm{f}}\right)$ of the solution was measured. The $\mathrm{pH}_{\mathrm{pzc}}$ was obtained by interpolating the data from the difference between $\mathrm{pH}_{\mathrm{i}}$ and $\mathrm{pH}_{\mathrm{f}}(\Delta \mathrm{pH})$ vs. $\mathrm{pH}_{\mathrm{i}}$. The stability of MHDHA in solid form was also evaluated at the different temperature ranging $30-600^{\circ} \mathrm{C}$ by thermogravimetry (TGA) instruments (DTG-60 Shimadzu) and different $\mathrm{pH}$ with the procedure as follows: one hundred $\mathrm{mg}$ of MHDHA and $\mathrm{HDHA}$ was exposed to solutions with medium $\mathrm{pH}$ ranging from 2.0 to 13.0. After stirring for $24 \mathrm{~h}$, the solid was separated with an external magnet and weighed carefully.

2.4. Effect of $p H$ and Ionic Strength. The effect of $\mathrm{pH}$ was studied by preparing a series of $25 \mathrm{~mL}$ of $\mathrm{Pb}$ (II) $25 \mathrm{mg} / \mathrm{L}$ that the $\mathrm{pH}$ was adjusted at 2.0, 3.0, 4.0, 5.0, 6.0, 7.0, and 8.0 by $\mathrm{NaOH}$ $0.01 \mathrm{M}$ or $\mathrm{HNO}_{3} 0.01 \mathrm{M}$ addition. Into each prepared $\mathrm{Pb}$ (II) solution, $20 \mathrm{mg}$ of the adsorbent was interacted and shaken for $2 \mathrm{~h}$. After the sorbent was separated, the remaining $\mathrm{Pb}$ (II) in solutions was quantified with AAS. The sorbed $\mathrm{Pb}$ (II) was considered as the difference between the initial and final amounts of $\mathrm{Pb}(\mathrm{II})$ in the solution. The optimum $\mathrm{pH}$ was determined by the most adsorbed $\mathrm{Pb}$ (II) to the sorbent. $\mathrm{Pb}$ (II) analysis in the solution was conducted by atomic absorption spectroscopy (AAS) (PerkinElmer 3110).

The effect of ionic strength on $\mathrm{Pb}$ (II) adsorption was conducted by preparing a 5 series of $25 \mathrm{~mL}$ of $\mathrm{Pb}$ (II) $25 \mathrm{mg} / \mathrm{L}$ at optimum $\mathrm{pH}$. Then, $\mathrm{NaCl}$ salt was added to each solution so that the final concentrations of $\mathrm{NaCl}$ were $0.005,0.01$, $0.05,0.1$, and $0.5 \mathrm{M}$. After $120 \mathrm{~min}$ stirring, the mixture was filtered and the filtrate was analyzed with AAS to obtain the adsorbed $\mathrm{Pb}(\mathrm{II})$.

2.5. Isotherm and Kinetics Sorption Experiment. The isotherm adsorption experiment was performed by contacting $20 \mathrm{mg}$ sorbent with $25 \mathrm{~mL}$ of artificial wastewater which has various $\mathrm{Pb}(\mathrm{II})$ concentrations (20, 40, 50, 60, 80, 100, 150, 200 , and $400 \mathrm{mg} / \mathrm{L}$ ) for $180 \mathrm{~min}$. The kinetics adsorption experiment was conducted by contacting $20 \mathrm{mg}$ of sorbent with $25 \mathrm{~mL}$ artificial wastewater containing $25 \mathrm{mg} / \mathrm{L} \mathrm{Pb}$ (II) for $5 \mathrm{~min}$. A similar procedure was conducted with variations in contact time: 10, 20, 30, 40, 50, 70, 90, 120, and $180 \mathrm{~min}$. An external magnet was used to attract MHDHA after the adsorption process. The residual $\mathrm{Pb}(\mathrm{II})$ in the solution was quantified by AAS.

2.6. Regeneration Studies. The reusability of MHDHA was checked by performing the five cycles of the adsorptiondesorption process. The desorption of $\mathrm{Pb}(\mathrm{II})$ was performed using $\mathrm{HNO}_{3} 0.1$. $\mathrm{M}$ as a desorbing agent. The $50 \mathrm{~mL}$ of $\mathrm{Pb}(\mathrm{II})$ $50 \mathrm{mg} / \mathrm{L}$ was shaken together with $50 \mathrm{mg}$ MHDHA for $120 \mathrm{~min}$ at $298 \mathrm{~K}$. The $\mathrm{Pb}(\mathrm{II})$-loaded MHDHA adsorbent was kept in the $100 \mathrm{~mL}$ conical flask (shaken for $120 \mathrm{~min}$ ) with the desorbing agent $(50 \mathrm{~mL})$. The HDHA adsorbent was separated by an external magnet retraction, washed with deionized water, and again repeated for five cycles of the adsorption-desorption process. Metal recovery (\%) was considered by the following equation [8]:

$$
\text { Metal recovery }(\%)=\frac{\text { metal ion desorbed }}{\text { metal ion adsorbed }} \times 100
$$

\section{Results and Discussion}

3.1. Characterization of HDHA. The successful HDHA extraction was indicated from high peaks at $250-300 \mathrm{~nm}$ and slopes with increasing wavelength with no specific peaks (Figure 1(a)). The smooth absorbance that decreases monotonously with the increasing wavelength between 250 and $800 \mathrm{~nm}$ of HDHA spectra is a characteristic spectrum of HA [43]. The steeper the slope indicates a high degree of humification [44]. There are three important regions to reveal the molecular properties of $\mathrm{HA}$ : at $280 \mathrm{~nm}$, this indicates the transformation of lignin and quinone into HA, at $460-480 \mathrm{~nm}$, this indicates organic material at the beginning of humification, and at $600-670 \mathrm{~nm}$, this is an indication of a strongly humified material with a high degree of aromatic groups [45]. Then, based on the $E_{2} / E_{6}$ (absorbance at $\left.280 \mathrm{~nm} / 664 \mathrm{~nm} ; A_{280} / A_{664}\right), E_{2} / E_{4}\left(A_{280} / A_{472}\right)$, and $E_{4} / E_{6}$ $\left(A_{472} / A_{664}\right)$ ratios, the degree of humification can be determined. The $E_{2} / E_{4}$ ratio reflects the relation between lignin and other materials at the beginning of the humification process; the $E_{2} / E_{6}$ ratios represent the proportion between nonhumified and mature humified materials, and the $E_{4} / E_{6}$ ratio asserts the degree of aromatic constituents of HA. The lower ratio values of $E_{2} / E_{4}, E_{2} / E_{6}$, and $E_{4} / E_{6}$ denote a high degree of aromatic condensation and a higher level of humification of organic material [46].

The high absorbance of peat soil HA (PSHA) at 250$300 \mathrm{~nm}$ with a sharp decrease clarifies a high degree of humification (Figure 1(a)). The lower ratio values of $E_{2} / E_{6}$ and $E_{2} / E_{4}$ in PSHA indicates that the peat soil is more humified than the horse dung material (Table 1) [41]. Both HDHA and PSHA have a similar ratio value of $E_{4} / E_{6}$ and agree with the categorized $E_{4} / E_{6}$ ratio of HA $(<5.0)$ [41]. The higher humification degree of PSHA (lower values of $E_{2} / E_{6}$ and $E_{2}$ $\left./ E_{4}\right)$ was also supported by the total acidity of the purified PSHA $(753 \mathrm{cmol} / \mathrm{kg})$ that had a higher value than that of 


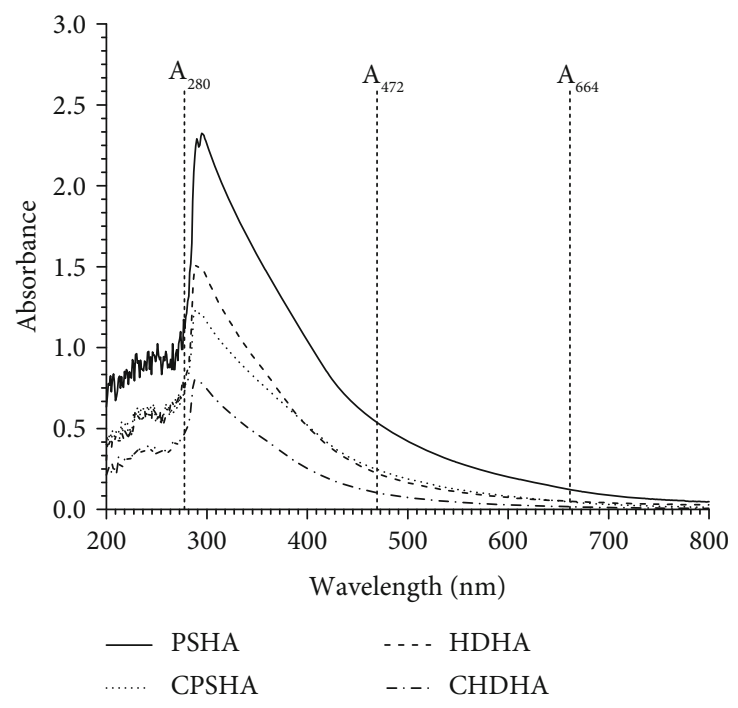

(a)

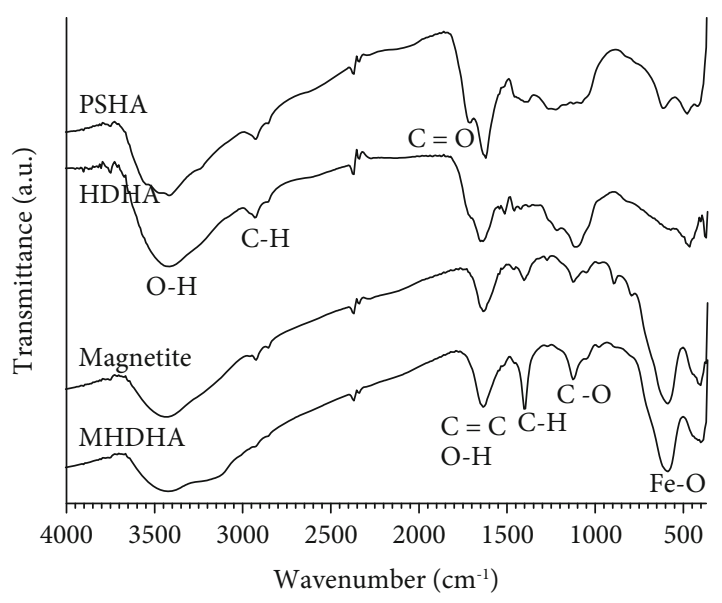

(b)

FIGURE 1: (a) Characteristic UV-Vis spectra of purified peat soil HA (PSHA), purified horse dung HA (HDHA), crude peat soil HA (CPSHA), and crude horse dung HA (CHDHA). (b) Characteristic functional groups of PSHA, HDHA, magnetite, and MHDHA.

TABLE 1: Characteristic parameters (yield, ash content, total acidity, and UV-Vis absorbance ratio) of extracted C-HDHA and HDHA compared with C-PSHA and PSHA.

\begin{tabular}{|c|c|c|c|c|c|c|c|c|}
\hline Materials & $\begin{array}{l}\text { Yield } \\
(\%)\end{array}$ & $\begin{array}{c}\text { Ash content } \\
(\%)\end{array}$ & $\begin{array}{l}\text { Total acidity } \\
(\mathrm{cmol} / \mathrm{kg})\end{array}$ & $\begin{array}{c}-\mathrm{COOH} \text { content } \\
(\mathrm{cmol} / \mathrm{kg})\end{array}$ & $\begin{array}{c}\text { Phenolic-OH content } \\
(\mathrm{cmol} / \mathrm{kg})\end{array}$ & $\begin{array}{l}\mathrm{UV}-\mathrm{V} \\
E_{2} / E_{6}\end{array}$ & $\begin{array}{c}\text { is abso } \\
\text { ratio } \\
E_{4} / E_{6}\end{array}$ & $\begin{array}{l}\text { bance } \\
E_{2} / E_{4}\end{array}$ \\
\hline $\begin{array}{l}\text { C- } \\
\text { HDHA }\end{array}$ & 6.6 & 24.76 & 493 & 316 & 177 & 17.41 & 5.39 & 3.23 \\
\hline C-PSHA & 43.2 & 36.97 & 690 & 432 & 258 & 29.88 & 6.04 & 4.95 \\
\hline HDHA & 4.3 & 9.92 & 513 & 330 & 183 & 16.89 & 4.38 & 3.85 \\
\hline PSHA & 25.9 & 3.41 & 753 & 472 & 281 & 10.16 & 4.41 & 2.30 \\
\hline
\end{tabular}

purified HDHA $(513 \mathrm{cmol} / \mathrm{kg})$. In addition, the purification process increases the total acidity by removing silicate/mineral impurities (evidenced by the lower ash content) of both crude PSHA and HDHA (Table 1). Meanwhile, the HDHA has a lower total acidity than PSHA but it is still in the reference range of HA from peat soil according to Stevenson [41]. Furthermore, HDHA exhibits to be more renewable, to have higher availability, to be cheaper, and to be greener than peat soil HA.

The FT-IR characterization of HDHA showed five characteristic peaks of $\mathrm{HA}$, i.e., $3400 \mathrm{~cm}^{-1}$ could be assigned to hydrogen bonding of -OH groups; $2900 \mathrm{~cm}^{-1}$ is designated for the stretching of $\mathrm{C}-\mathrm{H}$ aliphatic; $1720 \mathrm{~cm}^{-1}$ referred to $\mathrm{C}=\mathrm{O}$ stretching of $-\mathrm{COOH}$ groups; $1625 \mathrm{~cm}^{-1}$ is ascribed to aromatic $\mathrm{C}=\mathrm{C}, \mathrm{C}=\mathrm{O}$ of quinone groups, and aromatic rings formed by the hydrogen bond of $\mathrm{O}-\mathrm{H}$ groups; and $1200 \mathrm{~cm}^{-1}$ was associated with $\mathrm{O}-\mathrm{H}$ bending and $\mathrm{C}-\mathrm{O}$ stretching of $-\mathrm{COOH}$ groups (Figure $1(\mathrm{~b})$ ). The $\mathrm{Fe}-\mathrm{O}$ stretching vibrations of magnetite and MHDHA were significantly identified at $592 \mathrm{~cm}^{-1}$ [47]. In addition, the successful functionalization of $\mathrm{HDHA}$ on the magnetite surface was detected at $\sim 1625 \mathrm{~cm}^{-1}$ which indicated an interaction between $\mathrm{C}=\mathrm{O}$ and the iron oxide surface (Figure 1(b)) [12]. The absorption band at $1400 \mathrm{~cm}^{-1}$ was strongly assigned to $-\mathrm{CH}_{2}-$ scissoring, and the $1121 \mathrm{~cm}^{-1}$ band was assigned to the $\mathrm{C}-\mathrm{O}$ stretching of $-\mathrm{COOH}[10]$. The unobserved $\mathrm{C}=\mathrm{O}$ stretching in MHDHA (Figure 1(b)) as free $-\mathrm{COOH}$ at above $1700 \mathrm{~cm}^{-1}$ suggested the attachment of HDHA to magnetite through ligand-exchange interaction between $\mathrm{C}=\mathrm{O}$ and $\mathrm{Fe}_{3} \mathrm{O}_{4}$ surfaces [14]. Similarly, previous investigators reported that the linear thread-like polysaccharides could be strongly adsorbed by many oxide and aluminosilicate mineral surfaces [48].

The crystal properties of synthesized magnetite and MHDHA showed characteristic peaks with strong intensities emerging at $2 \theta$ angles corresponding to $30.1^{\circ}$ (220), $35.4^{\circ}(311), 43.1^{\circ}(400), 53.7^{\circ}(422), 57.0^{\circ}$ (511), and $62.7^{\circ}$ (411) (Figure 2(a)). The comparative diffractogram of MHDHA indicated good agreement with the standard diffractogram and spinel structures for magnetite (JCPDS 19-0629) [44, 45]. The crystallinity of MHDHA did not show any damage after being modified with HDHA although there was a decrease in peak intensity indicating low crystallinity. 

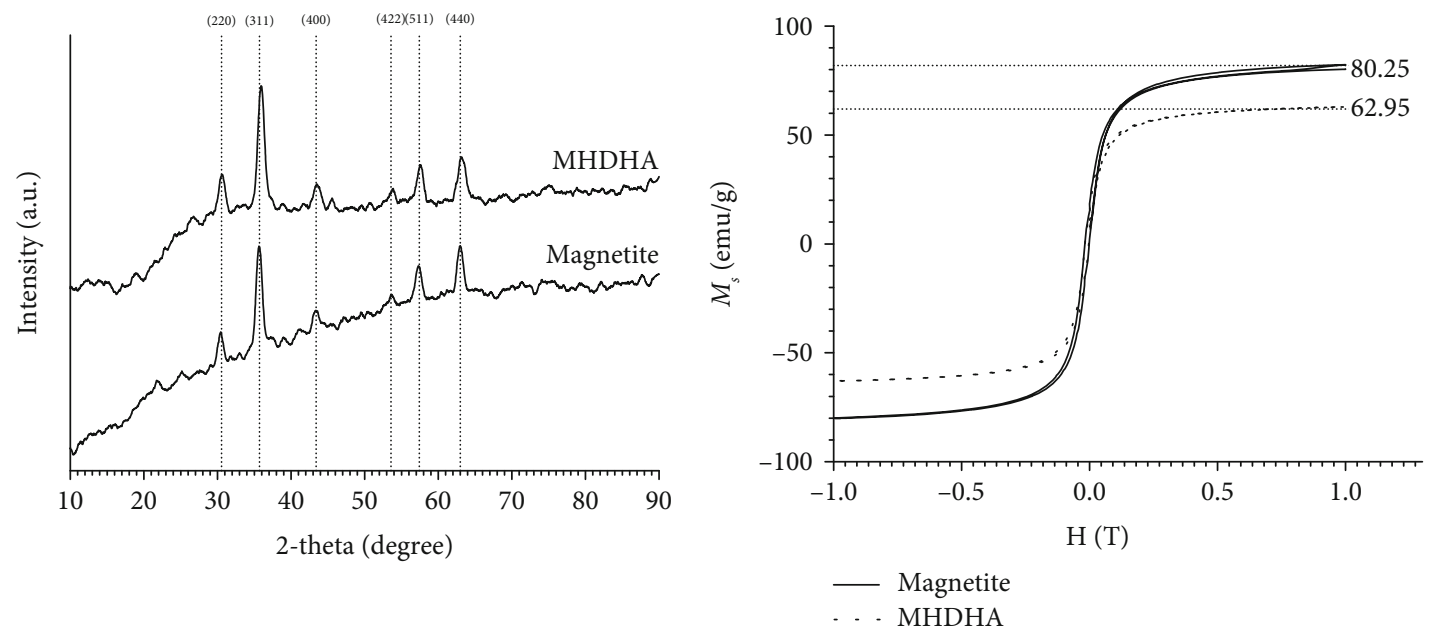

(a)

(b)

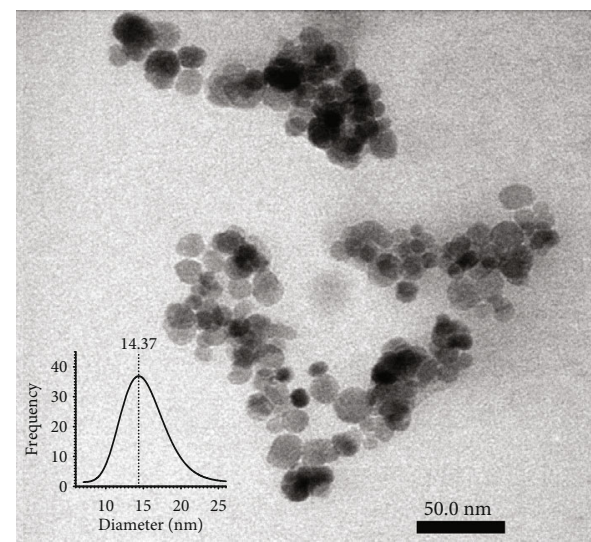

(c)

FIGURE 2: The diffractogram (a) and the magnetization hysteresis loop (b) of synthesized magnetite and MHDHA; TEM image of MHDHA and average particle size of MHDHA processed TEM image by free software ImageJ (inset picture) (c).

The magnetic properties, which were essential to ensure the separation process, were measured by graphing the hysteresis loop of synthesized bare magnetite and MHDHA (Figure 2(b)). The saturation magnetization $\left(M_{s}\right)$ value of MHDHA (62.95 emu/g) was lower than bare magnetite (80.25 emu/g). The $M_{s}$ value decreasing after magnetite functionalization was also reported by previous researchers [21, $41,42,44,45]$. In comparison, the $M_{s}$ value of synthesized MHDHA was quietly comparable with similar studies of magnetite-functionalized peat $\mathrm{HA}$, which were $61.2 \mathrm{emu} / \mathrm{g}$ [12], $63.31 \mathrm{emu} / \mathrm{g}$ [16], and $68.1 \mathrm{emu} / \mathrm{g}$ [10]. These magnetic properties allow easy and fast retraction of MHDHA from solution by an external magnet that makes HDHA an easyhandling adsorbent for $\mathrm{Pb}$ (II) in an aqueous solution. Also, no significant color change was observed after the MHDHA was stored in water for 14 days. This asserts that the HDHA modification prohibits the oxidation of magnetite because magnetite is easily oxidized to a brown suspension.

Elemental analysis by EDX Spectroscopy revealed that the surface composition $(w / w)$ was $67.07 \% \mathrm{Fe}, 29.41 \% \mathrm{O}$, and $3.51 \% \mathrm{C}$ for bare magnetite, whereas $53.91 \% \mathrm{Fe}$, $32.74 \% \mathrm{O}, 9.89 \% \mathrm{C}$, and $2.89 \% \mathrm{~N}$ for MHDHA (Table 2).
TABLE 2: Elemental analysis by energy dispersive X-ray spectroscopy (EDX) of magnetite and MHDHA.

\begin{tabular}{lcc}
\hline $\begin{array}{l}\text { Element } \\
\text { symbol/name/number }\end{array}$ & $\begin{array}{c}\text { Magnetite weight } \\
\text { concentration (\%) }\end{array}$ & $\begin{array}{c}\text { MHDHA weight } \\
\text { concentration (\%) }\end{array}$ \\
\hline Fe/iron/26 & 67.07 & 53.91 \\
O/oxygen/8 & 29.41 & 32.74 \\
C/carbon/6 & 3.51 & 9.89 \\
N/nitrogen/7 & - & 2.89 \\
Others & 0.01 & 0.57 \\
\hline
\end{tabular}

The content of oxygen, carbon, and nitrogen in MHDHA was significantly higher than that in bare magnetite. This depicts that the HDHA fractions containing atom carbon and oxygen or nitrogen-based functional groups were selectively incorporated on the surface of the magnetite during the MHDHA synthesis. The TEM image shows that MHDHA existed in spherical-shaped material with aggregation in a particular region (Figure 2(c)). The typical size of MHDHA processing by free software ImageJ was distributed from 6 to $25 \mathrm{~nm}$ with an average size of $\sim 14 \mathrm{~nm}$ (inset 


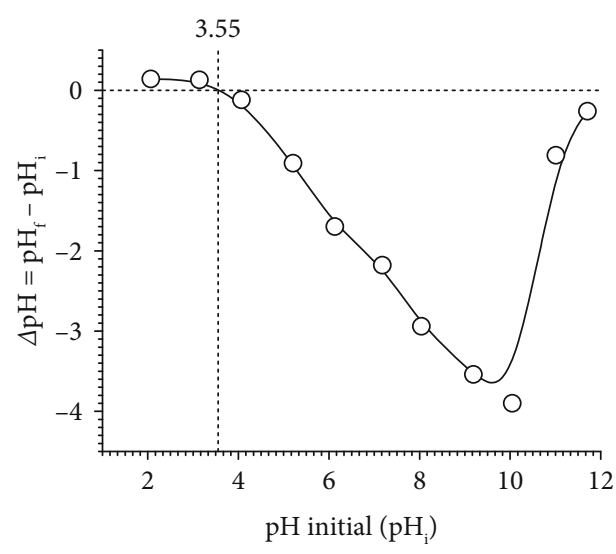

(a)

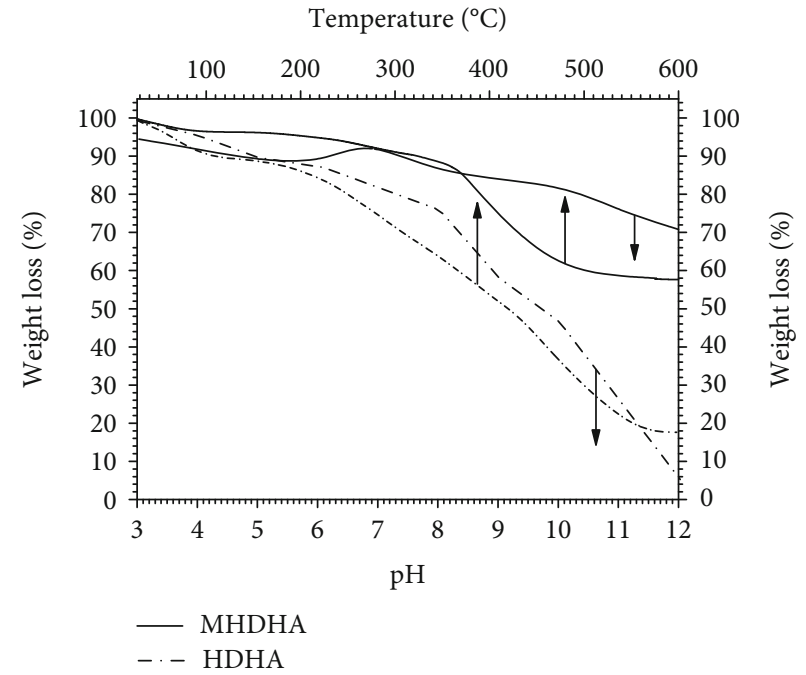

(b)

Figure 3: (a) Determination of the point of zero charge $\left(\mathrm{pH}_{\mathrm{pzc}}\right)$ of $48 \mathrm{~h}$ soaking solid MHDHA in medium with 2 the $.0-12.0 \mathrm{pH}$ range; (b) comparison of the medium $\mathrm{pH}$ and temperatures on the stability of HDHA and MHDHA.

Figure 2(c)). This evidence proves that nanosized MHDHA was successfully prepared. Supporting the finding, Illés and Tombácz reported that the synthesized $\mathrm{Fe}_{3} \mathrm{O}_{4} \mathrm{NPs}$ have a primary size of $\sim 10 \mathrm{~nm}$ with nonuniform size and fractal aggregates with an average of $\sim 120 \mathrm{~nm}$ in sol solution containing HA [49]. These findings demonstrate that the magnetitefunctionalized HDHA effectively reduces aggregation.

The point zero charged at varied $\mathrm{pH}\left(\mathrm{pH}_{\mathrm{pzc}}\right)$ is defined as a measurement of the $\mathrm{H}^{+}$ion movement towards and upwards the sorbent surfaces [42]. At this point, it is assumed that there is no $\mathrm{H}^{+}$ion movement and the sorbent is approximated in a neutral condition. The $\mathrm{pH}_{\mathrm{pzc}}$ of MHDHA was observed at $\mathrm{pH}$ 3.55. The change of $\mathrm{pH}$ medium after soaking the sorbent for $48 \mathrm{~h}$ is presented in Figure 3(a). At low $\mathrm{pH}$ (<3.55), $\mathrm{H}^{+}$ions move from the solution to the MHDHA active sites and increase the $\mathrm{pH}$ of the solution. However, at high $\mathrm{pH}(>3.55), \mathrm{H}^{+}$ions move from HDHA to the solution, resulting in a negative charge on the surface of HDHA and decreasing the $\mathrm{pH}$ of the medium. In comparison, the $\mathrm{p}$ $\mathrm{H}_{\text {pzc }}$ value of magnetite $\mathrm{HA}$ from the literature was 2.30 $[10,12]$. The MHDHA has a higher $\mathrm{pH}_{\mathrm{pzc}}$ value than the reference due to the lower total acidity of HDHA compared with the HA from peat. The low $\mathrm{pH}_{\mathrm{pzc}}$ denotes that the magnetite has been coated with HDHA, and the surface of MHDHA has been negatively charged at the relevant environmental $\mathrm{pH}(3.6-12.0)$. In addition, MHDHA is quite stable in solid form in the $\mathrm{pH}$ range of 2.0-12.0 (Figure 3(b)) to facilitate positively charged $\mathrm{Pb}(\mathrm{II})$.

The comparison of the medium $\mathrm{pH}$ stability of MHDHA and HDHA in solid form is presented in Figure 3(b) (left $y$ and bottom $x$ ). The MHDHA was relatively stable at $\mathrm{pH}<$ 8.0. Meanwhile, at higher $\mathrm{pH}(>8.0)$, the deprotonation of carboxylate and phenolic functional groups of magnetitefunctionalized HDHA makes $\mathrm{H}^{+}$ions to be unable to stabilize the $\mathrm{Fe}^{2+}$ ions in the magnetite core. In addition, the deprotonation of HDHA starts at pH 5.0 and continues until the solid dissolves at higher $\mathrm{pH}$. The thermal stability of MHDHA and that of HDHA were shown in Figure 3(b) (right $y$, top $x$ ). The water would be evaporated first at $105^{\circ} \mathrm{C}$, and then, the HDHA will be carbonated and incinerated with further increasing the temperature until about $600^{\circ} \mathrm{C}$, leaving the inorganic materials. The MHDHA and HDHA powders contained about $4 \%$ and $10 \%$ water, respectively, besides the inorganic materials. The MHDHA contained about $4 \%$ water and about $57 \%$ inorganic magnetite, so the loss on ignition was about $39 \%$, which mainly originated from HDHA. The functionalization of magnetite with HDHA obtained can improve the stability of HDHA. Furthermore, the high stability of MHDHA will support the use of MHDHA as a promising adsorbent for toxic $\mathrm{Pb}(\mathrm{II})$ and other contaminants.

3.2. Effect of $\mathrm{pH}$ and Ionic Strength on $\mathrm{Pb}(\mathrm{II})$ Adsorption. $\mathrm{pH}$ is essential in adsorption studies because it affects the binding of $\mathrm{Pb}$ (II) to MHDHA. Medium acidity can affect the surface charge of the sorbent and the structure of the sorbate speciation. The adsorption of $\mathrm{Pb}$ (II) is intimately dependent on medium $\mathrm{pH}$. The $\mathrm{Pb}(\mathrm{II})$ adsorbed was increased with increasing medium $\mathrm{pH}$ from 2.0 to 5.0 and decreased sharply when $\mathrm{pH}$ was above 5.0 (Figure 4(a)). This result was caused by the formation of solid $\mathrm{Pb}(\mathrm{OH})_{2}$ at $\mathrm{pH}>5.0$ based on the constant solubility product $\left(K_{\mathrm{sp}}\right)$ calculation [50]. At low $\mathrm{pH}\left(\mathrm{pH}<\mathrm{pH}_{\mathrm{pzc}}\right)$, the adsorbed $\mathrm{Pb}$ (II) was relatively low. This was caused by the MHDHA surface becoming positively charged due to protonation reaction and increases the competition between $\mathrm{H}^{+}$and the $\mathrm{Pb}$ (II) ions as cationic species. In contrast, at high $\mathrm{pH}\left(\mathrm{pH}>\mathrm{pH}_{\mathrm{pzc}}\right)$, the MHDHA surface becomes negatively charged (deprotonation) and electrostatic repulsion decreases, which enhances the positively charged $\mathrm{Pb}(\mathrm{II})$ adsorption [51]. The optimum $\mathrm{pH}$ of the adsorption system can be ascertained to attenuate $\mathrm{Pb}$ (II) in the solution to MHDHA at $\mathrm{pH}$ 5.0. Previous works on the 


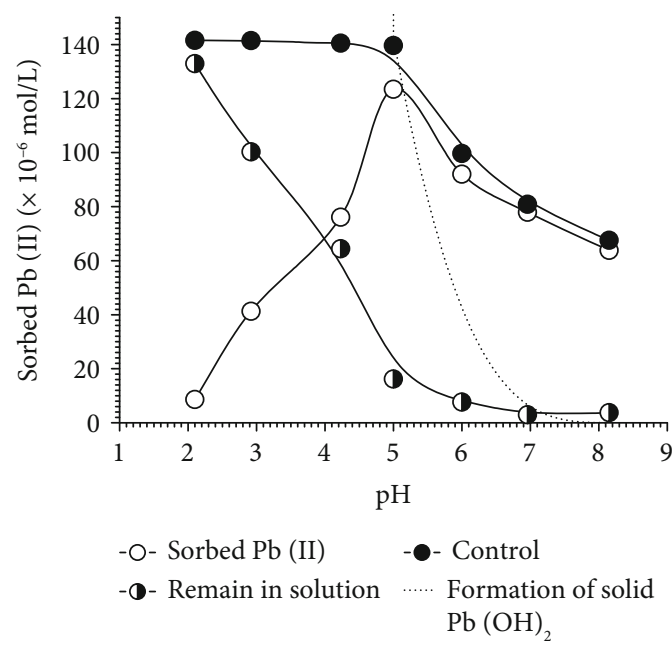

(a)

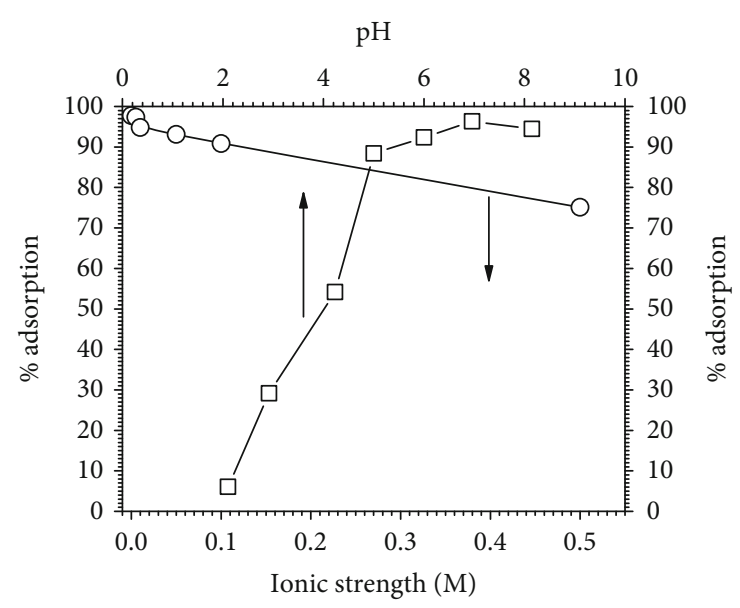

(b)

Figure 4: (a) Optimum $\mathrm{pH}$ of $\mathrm{Pb}(\mathrm{II})$ adsorption onto MHDHA; (b) \% adsorption of $\mathrm{Pb}(\mathrm{II})$ onto $\mathrm{MHDHA}$ as a function of $\mathrm{pH}$ and ionic strength.

$\mathrm{pH}$ optimum in $\mathrm{Pb}(\mathrm{II})$ adsorption on HA-based adsorbent, i.e., HA from peat (optimum $\mathrm{pH}$ 5.5) [52] and magnetic/HA chitosan (optimum pH 5.0) [53], show a similar optimum $\mathrm{pH}$ with this work.

In percentage (\%), at $\mathrm{pH}$ below the optimum $\mathrm{pH}$, the adsorption was significantly affected by the $\mathrm{pH}$. However, at $\mathrm{pH} 5.0-8.0$, the \% adsorption was relatively constant and more influenced by the ionic strength (Figure 4(b)). As shown, the high ionic strength has an effect of reducing the adsorption of $\mathrm{Pb}(\mathrm{II})$ on MHDHA. In literature, the low adsorption of divalent metal cations has been attributed to different factors [54]: (1) adsorbent active site blocking by salt, (2) repulsion between free positive-charge adsorbate and positively charged of adsorbent surfaces, (3) competition between positively charged species $\left(\mathrm{H}^{+}\right.$and $\left.\mathrm{Pb}^{2+}\right)$ and free adsorbate to the sorbent active sites, (4) lower formation of complexes/chelate with metal ions due to protonation of surface functional groups, and (5) combination of several of these factors. Considering the results, the adsorption of $\mathrm{Pb}$ (II) onto MHDHA seems to be affected by the first and third factors due to the ion exchange mechanisms between $\mathrm{Pb}$ (II) and MHDHA active sites. Previous works reported that the FTIR spectra were applied to characterize the changes of the functional group in metal ion adsorption [55-57]. The FTIR spectra of MHDHA before (Figure 1(b)) and after (Figure 5(c)) $\mathrm{Pb}$ (II) adsorption show the disappearing peaks at 1700 and $1200 \mathrm{~cm}^{-1}$ corresponding to the interaction between $\mathrm{Pb}(\mathrm{II})$ and carboxylate sites of MHDHA. The similar result of the FT-IR study on the $\mathrm{Pb}$ (II) interaction with the HA's active site has been reported by researchers that indicate the ion exchange mechanism [9-11].

3.3. Adsorption Isotherm Study. To optimize the performance of MHDHA, it is essential to establish the isotherm parameters of HDHA. Various isotherm models have been used to comprehend the isotherm parameters (adsorption capacity, equilibrium constant, and adsorption energy), i.e., Langmuir by plotting $C_{e} / q_{e}$ vs. $C_{e}$ (equation (2)), Freundlich by plotting $\ln q_{e}$ vs. In $C_{e}$ (equation (3)), Dubinin-Radushkevich (D-R) by plotting $\ln q_{e}$ vs. $\varepsilon^{2}$ (equation (4)) [58], and Temkin by plotting $q_{e}$ vs. $\ln C_{e}$ (equation (5)) [59].

$$
\begin{gathered}
\frac{C_{e}}{q_{e}}=\frac{1}{K_{L} b}+\frac{1}{b} C_{e}, \\
\ln q_{e}=\ln B+\frac{1}{n} \ln C_{e}, \\
\ln q_{e}=\ln q_{D}-B_{D} \varepsilon^{2}, \\
q_{e}=\frac{R T}{b_{T}} \ln A_{T}+\frac{R T}{b_{T}} \ln C_{e},
\end{gathered}
$$

where the $K_{L}\left(\mathrm{~L} \cdot \mathrm{mol}^{-1}\right)$ is the Langmuir equilibrium constant, $E_{L}(\mathrm{~kJ} / \mathrm{mol})$ is the monolayer adsorption energy $\left[E_{L}=R T \ln K_{L}\right], B(\mathrm{~mol} / \mathrm{g})$ is the Freundlich multilayer sorption capacity, $n$ is the heterogeneity parameter of the adsorbent surface, $b_{T}(\mathrm{~J} / \mathrm{mol}), A_{T}(\mathrm{~L} / \mathrm{g})$ are Temkin isotherm parameters, $R\left(8.314 \mathrm{~J} \cdot \mathrm{mol}^{-1} \cdot \mathrm{K}^{-1}\right)$ is the gas constant, and $T$ is the absolute temperature. Furthermore, $b(\mathrm{~mol} / \mathrm{g})$ is the Langmuir monolayer adsorbent-based saturated sorption capacity, $q_{e}(\mathrm{~mol} / \mathrm{g})$ is adsorbent based on the number of metal adsorbed on the active site of the adsorbent at equilibrium. $B_{D}\left(\mathrm{~mol}^{2} \cdot \mathrm{J}^{-2}\right)$ relates to the free energy of sorption per mol sorbate as it migrates to the surface to the adsorbent from an infinite distance in the solution, $\varepsilon\left(\mathrm{J}^{2} \cdot \mathrm{mol}^{-2}\right)$ is the Polanyi potential $\left[\varepsilon=R T \ln \left(1+1 / C_{e}\right)\right]$, and $q_{D}\left(\mathrm{~mol} / \mathrm{g}^{-1}\right)$ is the D-R isotherm constant, theoretical isotherm saturation capacity, which relates to the degree of sorbate sorption by the adsorbent surface.

Figure 6(a) shows the effect of initial concentration $\left(C_{0}\right)$ on the $\mathrm{Pb}(\mathrm{II})$ uptake by $\mathrm{MHDHA}$. The removal efficiency of MHDHA was found to be dependent on the $C_{0}$ of $\mathrm{Pb}(\mathrm{II})$. The adsorption of $\mathrm{Pb}(\mathrm{II})$ was increased with increasing initial concentration $\left(C_{0}\right)$ from 20 to $400 \mathrm{mg} / \mathrm{L}$ (Figure 6(a)). Thereafter, the removal efficacy slowly reached adsorption 


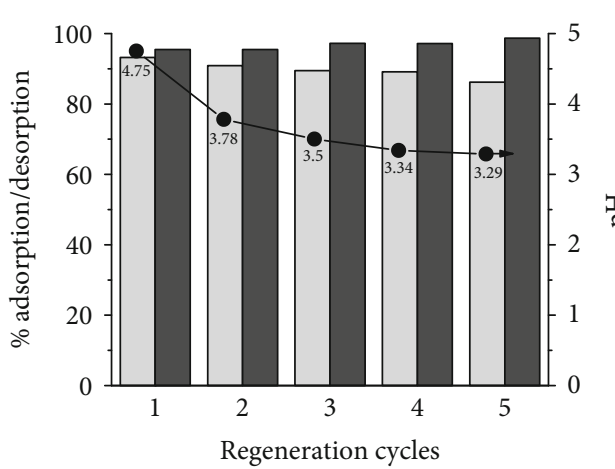

$\square$ Adsorption

Desorption

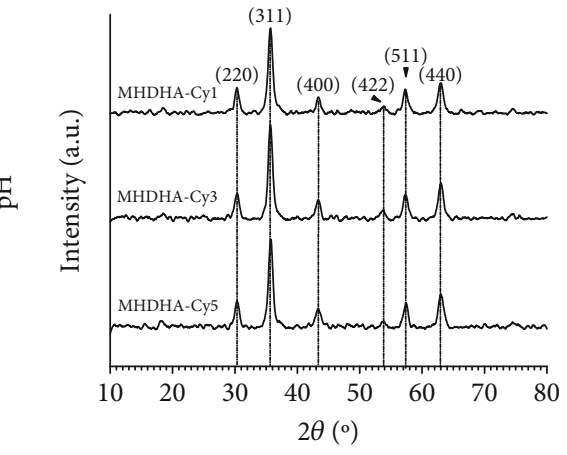

(b)

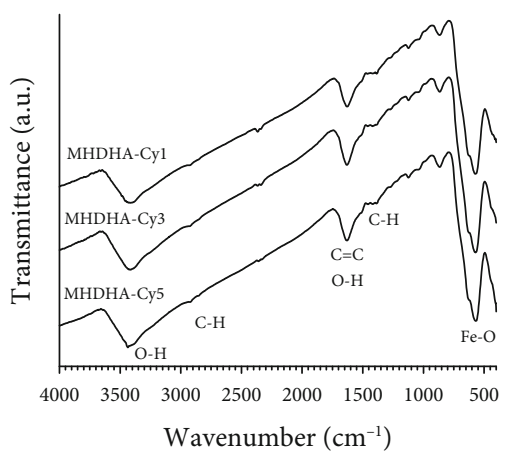

(c)

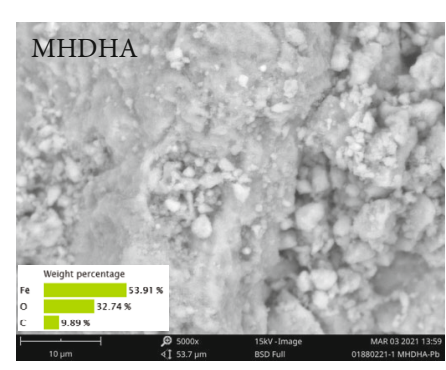

(d)

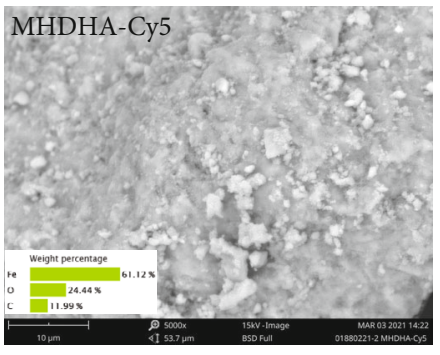

(e)

FIGURE 5: Regeneration study of MHDHA and pH change in each cycle (a); diffractogram of MHDHA (b); and FT-IR spectra after the first (MHDHA-Cy1), third (MHDHA-Cy3), and fifth cycle (MHDHA-Cy5) adsorption-desorption process (c); comparison of morphology and composition by SEM-EDX of original MHDHA (d); and that of MHDHA-Cy5 (e).

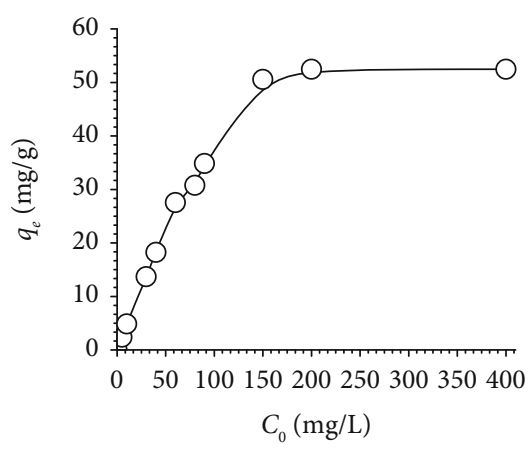

(a)

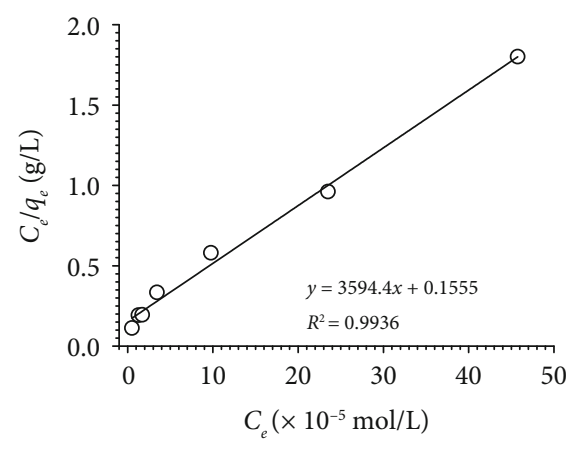

(b)

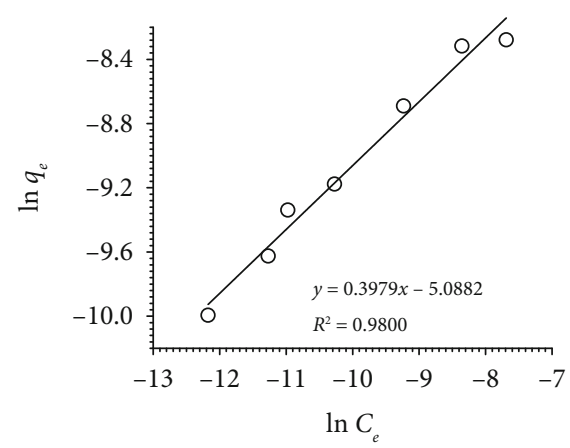

(c)

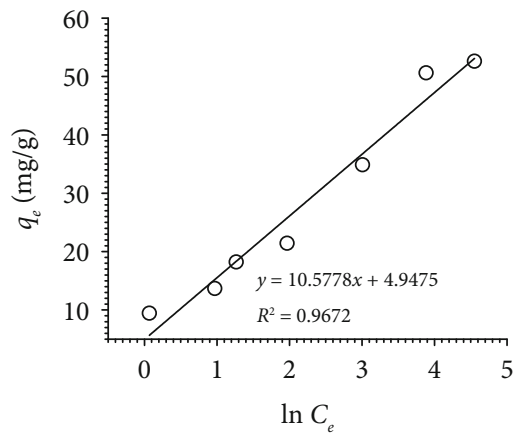

(d)

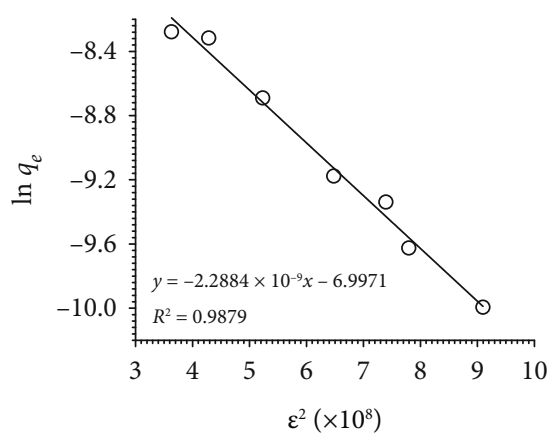

(e)

Figure 6: (a) The removal uptake of $\mathrm{Pb}(\mathrm{II})$ as the function of initial concentration $\left(C_{0}\right)$ and the linear plots of (b) Langmuir, (c) Freundlich, (d) Temkin, and (e) D-R isotherm models of $\mathrm{Pb}$ (II) sorption onto MHDHA. 
TABLE 3: Isotherm parameters of $\mathrm{Pb}(\mathrm{II})$ adsorption onto MHDHA.

\begin{tabular}{|c|c|c|c|c|c|}
\hline Isotherm models & & & therm parameters & & \\
\hline Ianomuir & $b\left(\times 10^{-5} \mathrm{~mol} / \mathrm{g}\right)$ & $b(\mathrm{mg} / \mathrm{g})$ & $K_{L}(\mathrm{~L} / \mathrm{mol})$ & $E_{L}(\mathrm{~kJ} / \mathrm{mol})$ & $R^{2}$ \\
\hline Langinum & 27.82 & 57.64 & 23115.11 & 24.90 & 0.9936 \\
\hline Ereundlich & $B\left(\times 10^{-}\right.$ & & $B(\mathrm{mg} / \mathrm{g})$ & $n$ & $R^{2}$ \\
\hline 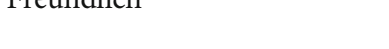 & 46 & & 1285.87 & 2.51 & 0.9800 \\
\hline Temkin & $b_{T}(\mathrm{~J}$ & & $A_{T}$ & & $R^{2}$ \\
\hline & 23 & & & & 0.9672 \\
\hline Dubinin-Radushkevich (D-R) & $q_{D}\left(\times 10^{-5} \mathrm{~mol} / \mathrm{g}\right)$ & $q_{D}(\mathrm{mg} / \mathrm{g})$ & $B_{D}\left(\times 10^{-9} \mathrm{~mol}^{2} / \mathrm{J}^{2}\right)$ & $E_{\mathrm{D}-\mathrm{R}}(\mathrm{kJ} / \mathrm{mol})$ & $R^{2}$ \\
\hline 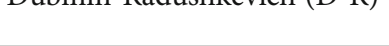 & 91.45 & 189.48 & 2.29 & 14.78 & 0.9879 \\
\hline
\end{tabular}

TABLE 4: Comparison of Langmuir sorption capacity $(b)$ in $\mathrm{Pb}(\mathrm{II})$ adsorption by various functionalized magnetite, - $\mathrm{HA}$, and other low-cost adsorbents at $298 \mathrm{~K}$.

\begin{tabular}{|c|c|c|c|}
\hline Adsorbents of $\mathrm{Pb}(\mathrm{II})$ & $b(\mathrm{mg} / \mathrm{g})$ & Optimum $\mathrm{pH}$ & References \\
\hline $\mathrm{Fe}_{3} \mathrm{O}_{4} /$ peat HA & 92.4 & 6.0 & [10] \\
\hline Polland peat HA & 82.3 & 5.0 & {$[68]$} \\
\hline $\mathrm{Ti}(\mathrm{IV})$ iodovanadate exchanger & 63.3 & 6.0 & [69] \\
\hline Starch peat HA & 58.0 & 6.0 & [67] \\
\hline MHDHA & 57.6 & 5.5 & Present work \\
\hline Magnetic coffee waste & 41.2 & 6.0 & {$[61]$} \\
\hline Magnetic cane biochar & 40.6 & 5.0 & {$[62]$} \\
\hline $\mathrm{Fe}^{3+} / \mathrm{Fe}^{2+}$ black cumin seed & 39.7 & 5.0 & [21] \\
\hline $\mathrm{Fe}_{3} \mathrm{O}_{4} @ \mathrm{SiO}_{2}$-IP polymer & 32.6 & 4.8 & {$[63]$} \\
\hline Plums biochar & 28.8 & 6.0 & {$[64]$} \\
\hline Amberlite-IR120 & 20.7 & 6.0 & {$[4]$} \\
\hline Kaolinite (Chikni Mitti) & 19.7 & 6.0 & {$[70]$} \\
\hline Indian HA soil & 19.2 & 6.0 & {$[66]$} \\
\hline SDSA $\mathrm{Zr}(\mathrm{IV})$ selenite & 18.4 & 6.0 & {$[71]$} \\
\hline HA peat & 15.0 & 5.5 & {$[52]$} \\
\hline Apricot biochar & 12.7 & 6.0 & {$[64]$} \\
\hline
\end{tabular}

equilibrium and there was no further adsorption of $\mathrm{Pb}(\mathrm{II})$. By correlating the $R^{2}$ value of the models, it can be achieved that Langmuir affords the best model for the sorption system, which stands on monolayer sorption to surfaces containing a finite number of identical active sites (Figure 6(b)). The monolayer adsorption capacity $(b)$ and energy $\left(E_{L}\right)$ of $\mathrm{Pb}(\mathrm{II})$ sorption onto MHDHA were $27.82 \times 10^{-5} \mathrm{~mol} / \mathrm{g}$ (equal to $57.64 \mathrm{mg} / \mathrm{g}$ ) and $24.90 \mathrm{~kJ} / \mathrm{mol}$, respectively (Table 3 ). The interaction of $\mathrm{Pb}(\mathrm{II})$ on MHDHA in this work followed the prediction by ion exchange interaction which referred to the categorized $E_{L}$ value: chemical interaction $(>80 \mathrm{~kJ} / \mathrm{mol})$, ion exchange $(<40 \mathrm{~kJ} / \mathrm{mol})$, and physical interaction $(<80 \mathrm{~kJ} / \mathrm{mol})[19,60]$. The $E_{L}$ value obtained in this work was $<40 \mathrm{~kJ} / \mathrm{mol}$, which implies that ion exchange dominates the $\mathrm{Pb}(\mathrm{II})$ sorption onto MHDHA.

The comparison of the monolayer sorption capacity $(b$ ) of $\mathrm{Pb}(\mathrm{II})$ sorption onto MHDHA and humic/peat-based adsorbents and other low-cost sorbents is summarized in Table 4. From the list in Table 4, it is clear that the synthesized MHDHA in this work had higher monolayer adsorption capacity than other magnetite functionalized materials [21, 61-63] and low-cost adsorbent [52, 64-66]. However, the capacity of MHDHA was relatively comparable to starch HA [67] and lower than $\mathrm{HA}$ peats (Polland) [68] and $\mathrm{Fe}_{3} \mathrm{O}_{4} / \mathrm{HA}$ [10]. The explanation of the lower monolayer adsorption capacity of MHDHA than $\mathrm{Fe}_{3} \mathrm{O}_{4}$ /peat $\mathrm{HA}[10]$ is that HDHA has lower total acidity $\left(-\mathrm{COO}^{-}\right.$and phenolic $\left.-\mathrm{OH}\right)$ than $\mathrm{HA}$ from natural peats [49-51], since $-\mathrm{COO}^{-}$and phenolic $-\mathrm{OH}$ are the most responsible sites in HA. Nevertheless, the MHDHA offers a greener and renewable source of HA with a relatively high adsorption capacity and easy separation by an external magnet without any additional steps after the adsorption process.

The important features of the Langmuir model can be expressed in terms of dimensionless constant sorption intensity, $R_{L}=1 /\left(1+K_{L} C_{0}\right)$, in which the $R_{L}$ value is classified by $R_{L}=0$ (irreversible), $0<R_{L}<1$ (favorable), and $R_{L}>1$ (unfavorable). When the $C_{0}$ of $\mathrm{Pb}$ (II) was in the range of 2.413 $\times 10^{-5}$ to $96.530 \times 10^{-5} \mathrm{~mol} / \mathrm{L}$, the calculated $R_{L}$ value changed from 0.639 to 0.042 . This shows that the adsorption of $\mathrm{Pb}(\mathrm{II})$ on MHDHA is favorable. 
The adsorption $\mathrm{Pb}$ (II) onto MHDHA was also evaluated by the Freundlich model to analyze the parameters associated with multilayer sorption. The value of $n$ found in this work (2.51) indicates that the adsorption process is relatively favorable because the $n$ value is above 1 (Table 3) [72]. The Freundlich model attributes both the homogenous and heterogeneous $\mathrm{Pb}(\mathrm{II})$ distribution on the MHDHA surface simultaneously. The Freundlich capacity $(B)$ indicates that the multilayer (or multienergy) of $-\mathrm{COOH}$, phenolic $-\mathrm{OH}$, and all the sites together with the strongest interaction is formed first in the first layer and then $\mathrm{Pb}$ (II) occupies the lower energy $[17,58]$. The $B$ value of $\mathrm{Pb}(\mathrm{II})$ on $\mathrm{MHDHA}$ was $465.90 \times 10^{-5} \mathrm{~mol} / \mathrm{g}$ (equal to $1285.87 \mathrm{mg} / \mathrm{g}$ ), about 16.7 layers compared with the monolayer adsorption. Therefore, the adsorption properties of $\mathrm{Pb}$ (II) onto MHDHA seem to involve more than one mechanism considering other active sites besides $-\mathrm{COOH}$ and phenolic $-\mathrm{OH}$.

The Temkin isotherm explains the adsorbate-adsorbent interaction based on the assumption that there is an indirect relationship between the adsorption energy and the adsorbate-adsorbent interaction $[60,61]$. As exhibited in Table 3, the value of the Temkin constant, $b_{T}$, related to the adsorption energy was $234.22 \mathrm{~J} / \mathrm{mol}$. Correlated with the multilayer adsorption, the value of $b_{T}$ can be interpreted as the adsorption energy of the outer layer of $\mathrm{Pb}(\mathrm{II})$ adsorption onto MHDHA [73]. The $R^{2}$ value of the Temkin model which is lower than the Langmuir model indicates that the Temkin model supports the multilayer sorption description.

The D-R isotherm is possible to analyze the high degree of regularity [74]. The $\mathrm{D}-\mathrm{R}$ theoretical isotherm saturation capacity, $q_{D}$, of $\mathrm{Pb}(\mathrm{II})\left(91.45 \times 10^{-5} \mathrm{~mol} / \mathrm{g}\right.$ or equal to $189.48 \mathrm{mg} / \mathrm{g}$ ) indicates that $\mathrm{Pb}(\mathrm{II})$ is saturated in a multilayer way on the active site of MHDHA. The saturated $\mathrm{Pb}$ (II) layer is approximately 3.89 times greater than the first monolayer. It is known that the magnitude of $\mathrm{D}-\mathrm{R}$ adsorption energy, $E_{\mathrm{D}-\mathrm{R}}\left(E_{\mathrm{D}-\mathrm{R}}=1 /\left(2 B_{D}\right)^{1 / 2}\right)$ is useful for estimating the type of adsorption. If the value of $E_{\mathrm{D}-\mathrm{R}}$ is below $8 \mathrm{~kJ} / \mathrm{mol}$, the adsorption type can be explained by physical adsorption, between 8 and $16 \mathrm{~kJ} / \mathrm{mol}$, the adsorption type can be explained by ion exchange, and over $16 \mathrm{~kJ} / \mathrm{mol}$, the adsorption type can be explained by a stronger chemical adsorption than ion exchange $[75,76]$. The values of $E_{\mathrm{D}-\mathrm{R}}$ found in this study was $14.78 \mathrm{~kJ} / \mathrm{mol}$ (Table 3 ), which implied that ion exchange is the main mechanism involved in the adsorption process. This result is in line with the main interaction of $\mathrm{Pb}(\mathrm{II})$ and MHDHA obtained from $E_{L}$.

3.4. Adsorption Kinetics Study. Investigation of the ratecontrolling $\mathrm{Pb}(\mathrm{II})$ adsorption onto MHDHA was studied by the Lagergren pseudo-first-order (equation (6)) [77] and Ho pseudo-second-order (equation (7)) [78] kinetics models. In addition, the correlation of adsorption rate constant $\left(k_{a}\right)$ and the isotherm equilibrium constant $(K)$ was investigated by the kinetics model proposed by Santosa (equation (8)) [9] and Rusdiarso-Basuki-Santosa (RBS) (equation (9)) [37, 79] kinetics models through the $K=k_{a} / k_{d}$ relationship. The nomenclatures of the symbols are $q_{e}$ and $q_{t}\left(\mathrm{~mol} \cdot \mathrm{g}^{-1}\right)$ which represent the amount adsorbate that adsorbed at equilibrium and time $t(\mathrm{~min})$, respectively; $C_{0}\left(\mathrm{~mol} \cdot \mathrm{L}^{-1}\right)$ and $C_{e}\left(\mathrm{~mol} \cdot \mathrm{L}^{-1}\right)$ denote the initial concentration of sorbate and the equilibrium concentration of sorbate on sorbent in the solution, respectively; $x\left(\mathrm{~mol} \cdot \mathrm{L}^{-1}\right)$ and $x_{e}\left(\mathrm{~mol} \cdot \mathrm{L}^{-1}\right)$ are sorbate based on the amount of sorbate sorbed on the sorbent's active site at time $t$ and equilibrium, respectively; $X\left(\mathrm{~g} \cdot \mathrm{L}^{-1}\right)$ in Santosa's kinetics model is $w / v m_{r}$, where $w(\mathrm{~g})$ is the mass of the sorbent, $v(\mathrm{~L})$ is the volume of sorption medium, and $m_{r}$ is the molar weight of sorbate; $C_{b}\left(\mathrm{~mol} \cdot \mathrm{L}^{-1}\right)$ is the concentration of Langmuir capacity and $C_{b}$ is calculated from $b w / v ; k_{\mathrm{Lag}}$ $\left(\mathrm{min}^{-1}\right), k_{\mathrm{Ho}}\left(\mathrm{g} \cdot \mathrm{mol}^{-1} \cdot \mathrm{min}^{-1}\right), k_{s}\left(\mathrm{~L} \cdot \mathrm{mol}^{-1} \cdot \mathrm{min}^{-1}\right)$, and $k_{a}$ $\left(\mathrm{L} \cdot \mathrm{mol}^{-1} \cdot \mathrm{min}^{-1}\right)$ are the Lagergren, Ho, Santosa, and RBS rate constants, respectively.

$$
\begin{gathered}
\ln \left(q_{e}-q_{t}\right)=\ln q_{e}-k_{\mathrm{Lag}} t, \\
\frac{t}{q_{t}}=\frac{1}{k_{\mathrm{Ho}}\left(q_{e}^{2}\right)}+\frac{1}{q_{e}} t, \\
\frac{1}{C_{0}-X q_{e}} \ln \left(\frac{q_{e}\left(C_{0}-X q_{t}\right)}{C_{0}\left(q_{e}-q_{t}\right)}\right)=k_{s} t, \\
\ln \left(\frac{C_{0} C_{b}-x_{e} x}{x_{e}-x}\right)=k_{a}\left(\frac{C_{0} C_{b}-x_{e}{ }^{2}}{x_{e}}\right) t-\ln \left(\frac{x_{e}}{C_{0} C_{b}}\right) .
\end{gathered}
$$

The adsorption rate of $\mathrm{Pb}(\mathrm{II})$ onto $\mathrm{MHDHA}$ was studied in time intervals of 5-180 min as shown in Figure 7(a). The $\mathrm{Pb}$ (II) ions were rapidly uptake in the first $20 \mathrm{~min}$ and slowly continue increasing up to 90 min reaction. The slow adsorption stage was caused by the smaller differences in concentration gradients that finally attained the equilibrium condition after $120 \mathrm{~min}$. An increase in $\mathrm{Pb}$ (II) adsorption was observed in MHDHA due to the probability of $\mathrm{Pb}$ (II) occupying a vacant site on the adsorbent, where there was plenty of unsaturated vacant sites that resulted in rapid initial adsorption. However, as time continues, vacant sites get saturated therefore adsorption performance of MHDHA decreased equilibrium condition. The adsorbed $\mathrm{Pb}$ (II) at equilibrium was found to be $52.47 \mathrm{mg} / \mathrm{g}$ under the following experimental condition: $25 \mathrm{~mL}$ of solution at $298 \mathrm{~K}$ using an adsorbent dosage of $20 \mathrm{mg}$ with an initial concentration of $25 \mathrm{mg} / \mathrm{L}$ at optimum $\mathrm{pH}$ 5.5.

The application of experimental data to equations (5)-(8) and the calculated values of corresponding parameters are shown in Figures 7(b)-7(e), respectively, and Table 5. Compared to the Lagergren pseudo-first-order (Figure 7(b)), Santosa (Figure $7(\mathrm{~d})$ ), and RBS (Figure 7(e)) models, $\mathrm{Pb}(\mathrm{II}$ ) sorption kinetics were better described by the Ho pseudosecond-order model (Figure $7(\mathrm{c})$ ), whose correlation coefficients (0.9999) were higher than those of the kinetics model. The calculation of $q_{e}$ (Calc. $\left.q_{e}\right)$ of Ho $\left(4.89 \times 10^{-5} \mathrm{~mol} / \mathrm{g}\right)$ (Table 5) was also the closest to the experimental $q_{e}$ (Exp. $q_{e}=4.88 \times 10^{-5} \mathrm{~mol} / \mathrm{g}$ ) in this work. Based on these findings, the best model representing the empirical kinetics data was the Ho kinetics model. This indicates that the adsorption process follows the pseudo-second-order mechanism. In this mechanism, the adsorption process depends on the active site 


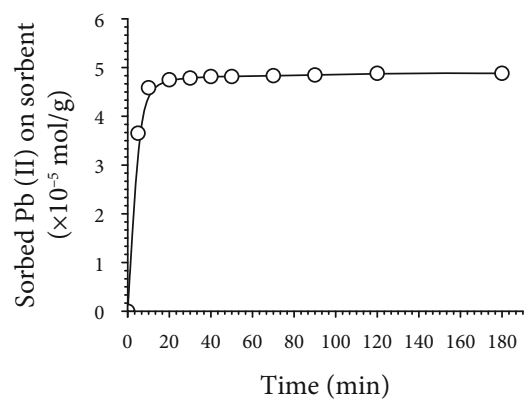

(a)

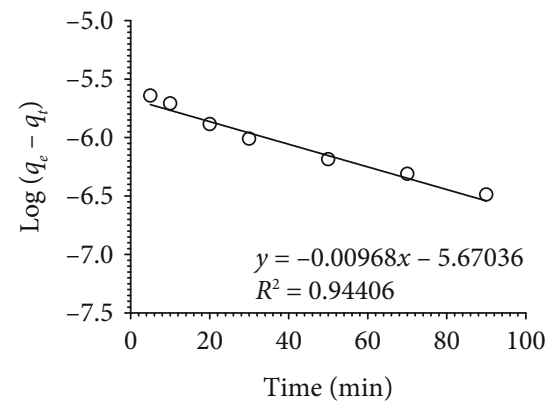

(b)

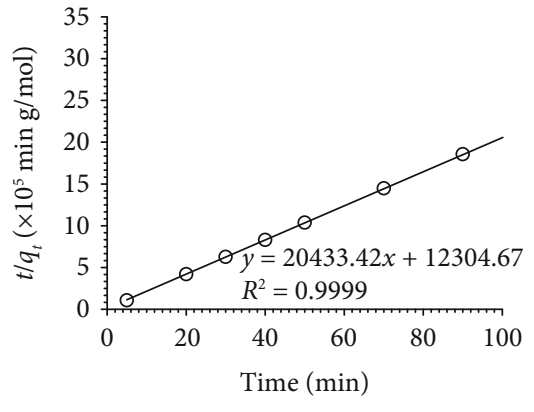

(c)

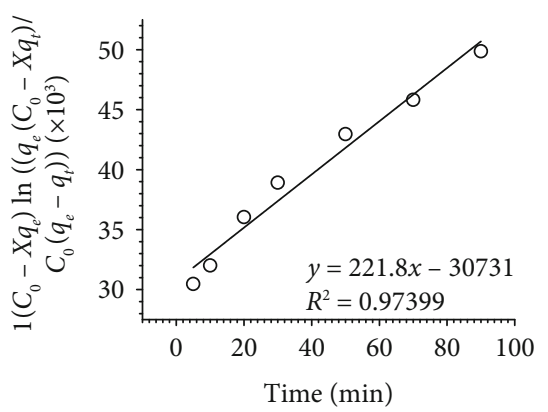

(d)

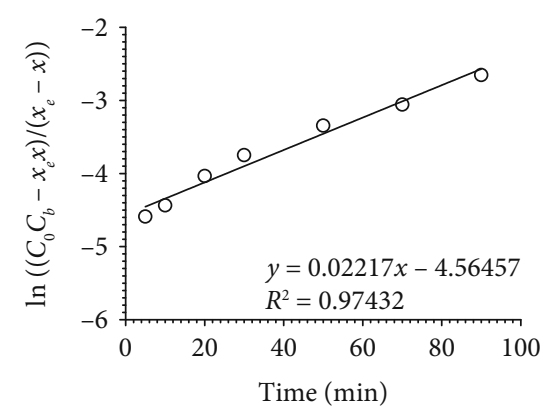

(e)

Figure 7: (a) Profile of $\mathrm{Pb}(\mathrm{II})$ uptake onto MHDHA as a function of time and adsorption kinetics plot of $25 \mathrm{mg} / \mathrm{L}$ ( $0.12 \mathrm{mmol} / \mathrm{L}$ ) $\mathrm{Pb}$ (II) onto $20 \mathrm{mg}$ MHDHA by (b) Lagergren, (c) Ho, (d) proposed Santosa, and (e) proposed RBS kinetics model.

TABLE 5: Kinetics parameters of $\mathrm{Pb}(\mathrm{II})$ adsorption onto MHDHA.

\begin{tabular}{|c|c|c|c|c|c|}
\hline \multirow{3}{*}{$\begin{array}{l}\text { Kinetics model } \\
\text { Lagergren }\end{array}$} & \multicolumn{5}{|c|}{ Kinetics adsorption parameters } \\
\hline & Calc. $q_{e}\left(\times 10^{-5} \mathrm{~mol} / \mathrm{g}\right)$ & $k_{\text {Lag }}\left(\min ^{-1}\right)$ & $k_{d}$ & $K$ & $R^{2}$ \\
\hline & 0.214 & 0.022 & - & - & 0.9441 \\
\hline \multirow{2}{*}{ Ho } & Calc. $q_{e}\left(\times 10^{-5} \mathrm{~mol} / \mathrm{g}\right)$ & $k_{\mathrm{Ho}}\left(\mathrm{g} \cdot \mathrm{mol}^{-1} \cdot \mathrm{min}^{-1}\right)$ & $k_{d}$ & $K$ & $R^{2}$ \\
\hline & 4.89 & 33932.66 & - & - & 0.9999 \\
\hline \multirow{2}{*}{ Santosa } & Calc. $q_{e}$ & $k_{s}\left((\mathrm{~mol} / \mathrm{L})^{-1} \cdot \mathrm{min}^{-1}\right)$ & $k_{d s}\left(\times 10^{-5} \cdot \min ^{-1}\right)$ & $K_{S}(\mathrm{~mol} / \mathrm{L})^{-1}$ & $R^{2}$ \\
\hline & - & 221.80 & 6.03 & $3.68 \times 10^{6}$ & 0.9740 \\
\hline \multirow{2}{*}{ RBS } & Calc. $q_{e}\left(\times 10^{-5} \mathrm{~mol} / \mathrm{g}\right)$ & $k_{\mathrm{RBS}}\left((\mathrm{mol} / \mathrm{L})^{-1} \cdot \mathrm{min}^{-1}\right)$ & $k_{d}\left(\times 10^{-4} \cdot \min ^{-1}\right)$ & $K_{\mathrm{RBS}}(\mathrm{mol} / \mathrm{L})^{-1}$ & $R^{2}$ \\
\hline & 0.2664 & 47.10 & 6.98 & 67478.51 & 0.9743 \\
\hline
\end{tabular}

of the adsorbent and the properties of the adsorbate. One of the properties is the initial concentration of adsorbate $\left(C_{0}\right)$. Previous studies have shown that the Ho kinetics model is appropriate at low $C_{0}$. In contrast, at high $C_{0}$, the Lagergren model is more suitable than the Ho model to represent the adsorption process $[78,80-84]$. This work used a low $C_{0}$ $(0.12 \mathrm{mmol} / \mathrm{L})$ and was in accordance with the previous findings.

The low $C_{0}$ value might affect the lower $R^{2}$ of the Lagergren model $\left(R^{2}=0.9441\right)$ (Table 5). The Lagergren model also generates the Calc. $q_{e}\left(0.214 \times 10^{-5} \mathrm{~mol} / \mathrm{g}\right)$, which is quite far from the Exp. $q_{e}\left(4.89 \times 10^{-5} \mathrm{~mol} / \mathrm{g}\right)$. Nevertheless, the adsorption rate constants of $\mathrm{Ho}\left(k_{\mathrm{Ho}}\right)$ and Lagergren $\left(k_{\mathrm{Lag}}\right)$ are an independent parameter because there is no crosssectional method to examine these parameters. Thus, the Santosa and RBS kinetics models have been applied to cross- examine the adsorption rate constant to the equilibrium constant through $K=k_{a} / k_{d}$ relationship. The results showed that both the Santosa and RBS models had a lower $R^{2}$ value than the Ho model. These $R^{2}$ values are quite similar to the Lagergren model indicating that the Santosa and RBS models have a similar condition of $C_{0}$ that is excess $C_{0}$. Furthermore, from the $K_{\mathrm{RBS}}$ value $(67478.51 \mathrm{~L} / \mathrm{mol})$, the predicted adsorption energy $\left(E_{\mathrm{RBS}}=27.55 \mathrm{~kJ} / \mathrm{mol}\right)$ is fairly comparable to the $E_{L}(24.90 \mathrm{~kJ} / \mathrm{mol})$.

3.5. Regeneration Studies. The regeneration studies represent the probable reusability of MHDHA as an adsorbent. The MHDHA adsorbent was only a loss of less than $15 \%$ of $\%$ adsorption after reuse for five successive cycles (Figure 5(a)). The adsorption-desorption percentage proves that the MHDHA possesses a virtuous regeneration ability. 
To strengthen the claims, the XRD (Figure 5(b)), FT-IR (Figure 5(c)), and SEM-EDX (Figures 5(d) and 5(e)) analyses show that there was no significant change in the crystallinity, functional group, morphology, and composition of MHDHA adsorbent, respectively, after five consecutive cycles of the adsorption-desorption process. The unobserved crystallinity damage implies that there is no significant change in the magnetic strength value and makes the HDHA remain easy and quick to separate by an external magnet. Therefore, the MHDHA is potentially efficient, economically effective, and easily separable adsorbent for lead-contaminated wastewater treatment.

The measurement of $\mathrm{pH}$ solution in each adsorption cycle showed that the $\mathrm{pH}$ was decreased constantly from optimum $\mathrm{pH}(\mathrm{pH}=5.50$, before the adsorption process $)$ to 3.29 in the fifth cycle (Figure 5(a)). A possible explanation of this result is that there is an ion-exchange mechanism between $\mathrm{H}^{+}$of MHDHA's active site (dominated by the carboxylic and phenolic group) and $\mathrm{Pb}(\mathrm{II})$. At the adsorption process, the $\mathrm{H}^{+}$ions replaced by the $\mathrm{Pb}$ (II) ions and the moved $\mathrm{H}^{+}$onto solution lead to increasing the acidity (decreasing in $\mathrm{pH}$ value). The reverse process occurred in the desorption step.

\section{Conclusions}

The green horse dung HA (HDHA) has been extracted and characterized by UV-Vis spectrophotometer, FT-IR, and total acidity. Functionalization of magnetite by HDHA has been successfully prepared by coprecipitation procedures based on FT-IR, XRD, TEM, SEM-EDX, TGA, and VSM characterization. The functionalization process improves the stability from $96 \%$ of original HDHA dissolved to less than 30\% HDHA dissolved after magnetite functionalization at $\mathrm{pH} 12$. Also, the MHDHA has only $10 \%$ weight loss compared with the original HDHA ( $88 \%$ weight loss) at $600^{\circ} \mathrm{C}$. The MHDHA was easy to retract by an external magnet after the adsorption process within a few minutes with the $62.95 \mathrm{emu} / \mathrm{g}$ magnetic strength without additional process, i.e., centrifugation or separation by the filter paper. The adsorbed $\mathrm{Pb}$ (II) onto MHDHA was influenced by the $\mathrm{pH}$, and the ionic strength with the adsorption rate was rapidly uptake in the first $20 \mathrm{~min}$ and attained equilibrium in $120 \mathrm{~min}$. The kinetics data of the adsorption rate was agreed well with the Ho pseudo-second-order model. The removal uptake of $\mathrm{Pb}(\mathrm{II})$ ions increased when the initial concentration was increased and fitted with the Langmuir isotherm model. The adsorption capacity of the $\mathrm{Pb}$ (II) uptake was $2.78 \times 10^{-4} \mathrm{~mol} / \mathrm{g}$ (equal to $57.64 \mathrm{mg} / \mathrm{g}$ ) through monolayer adsorption. The main interaction involved in the adsorption process was the ion exchange based on the value of DubininRadushkevich adsorption energy, $E_{\mathrm{D}-\mathrm{R}}(14.78 \mathrm{~kJ} / \mathrm{mol})$. The regeneration studies of MHDHA exhibited that there was no significant chemical and physical properties change after five consecutive cycles of the adsorption-desorption process. Therefore, MHDHA can be used as a promising low-price, green, and easy-handling adsorbent for the $\mathrm{Pb}$ (II) uptake from aqueous solution since the MHDHA showed good performance compared with other magnetized low-cost adsor- bents. Further, the research by improving and examining MHDHA to other adsorbates (dyes, organic contaminant, and other heavy metal ions) is needed to investigate the further performance of the MHDHA.

\section{Data Availability}

The raw data was generated at the Department of Chemistry, Universitas Gadjah Mada. The data supporting the findings of this study may be made available from the corresponding author upon request.

\section{Conflicts of Interest}

The authors declare that there is no conflict of interest regarding the publication of this paper.

\section{Acknowledgments}

R.B. gratefully acknowledges the LPDP (Indonesia Endowment Fund for Education) BPI Program for the financial support of this work and the Ph.D. scholarship (KET3/LPDP.3/2018). B.R. thanks Universitas Gadjah Mada (UGM) for partially financing this work through the RTA 2020 Program (Grant number: 607/UN1/DITLIT/DIT$\mathrm{LIT} / \mathrm{PT} / 2020)$.

\section{References}

[1] V. Masindi and K. L. Muedi, "Environmental contamination by heavy metals," Heavy metals, vol. 10, pp. 115-132, 2018.

[2] M. Hanbali, H. Holail, and H. Hammud, "Remediation of lead by pretreated red algae: adsorption isotherm, kinetic, column modeling and simulation studies," Green Chemistry Letters and Reviews, vol. 7, no. 4, pp. 342-358, 2014.

[3] X. Liu, H. Pang, X. Liu et al., "Orderly Porous Covalent Organic Frameworks-based Materials: Superior Adsorbents for Pollutants Removal from Aqueous Solutions," The Innovation, vol. 2, no. 1, article 100076, 2021.

[4] M. Naushad and Z. A. ALOthman, "Separation of toxic Pb2 + metal from aqueous solution using strongly acidic cationexchange resin: analytical applications for the removal of metal ions from pharmaceutical formulation," Desalination and Water Treatment, vol. 53, no. 8, pp. 2158-2166, 2013.

[5] N. S. Alharbi, T. Hayat, S. O. Rabah et al., "Efficient elimination of environmental pollutants through sorption-reduction and photocatalytic degradation using nanomaterials," Frontier Chemical Science and Engineering, vol. 14, no. 6, pp. 11241135, 2020.

[6] P. Hałas, D. Kołodyńska, A. Płaza, M. Gęca, and Z. Hubicki, "Modified fly ash and zeolites as an effective adsorbent for metal ions from aqueous solution," Adsorption Science \& Technology, vol. 35, no. 5-6, pp. 519-533, 2017.

[7] J. Anwar, Waheed-uz-Zaman, M. Salman et al., "Removal of chromium from water using pea waste - a green approach," Green Chemistry Letters and Reviews, vol. 3, no. 3, pp. 239243, 2010.

[8] G. Sharma and M. Naushad, "Adsorptive removal of noxious cadmium ions from aqueous medium using activated carbon/zirconium oxide composite: Isotherm and kinetic modelling," Journal of Molecular Liquids, vol. 310, article 113025, 2020. 
[9] S. J. Santosa, "Sorption kinetics of Cd(II) species on humic acid-based sorbent," Clean-Soil, Air, Water, vol. 42, no. 6, pp. 760-766, 2014.

[10] J. F. Liu, Z. S. Zhao, and G. B. Jiang, "Coating $\mathrm{Fe}_{3} \mathrm{O}_{4}$ magnetic nanoparticles with humic acid for high efficient removal of heavy metals in water," Environmental Science and Technology, vol. 42, no. 18, pp. 6949-6954, 2008.

[11] S. J. Santosa, D. Siswanta, S. Sudiono, and R. Utarianingrum, "Chitin-humic acid hybrid as adsorbent for Cr(III) in effluent of tannery wastewater treatment," Applied Surface Science, vol. 254, no. 23, pp. 7846-7850, 2008.

[12] L. Peng, P. Qin, M. Lei et al., "Modifying $\mathrm{Fe}_{3} \mathrm{O}_{4}$ nanoparticles with humic acid for removal of Rhodamine B in water," Journal of Hazardous Materials, vol. 209-210, pp. 193-198, 2012.

[13] X. Zhang, P. Zhang, Z. Wu, L. Zhang, G. Zeng, and C. Zhou, "Adsorption of methylene blue onto humic acid-coated $\mathrm{Fe}_{3} \mathrm{O}_{4}$ nanoparticles," Colloids and Surfaces A: Physicochemical and Engineering Aspects, vol. 435, pp. 85-90, 2013.

[14] R. P. Chen, Y. L. Zhang, X. Y. Wang, C. Y. Zhu, A. J. Ma, and W. M. Jiang, "Removal of methylene blue from aqueous solution using humic-acid coated magnetic nanoparticles," Desalination and Water Treatment, vol. 55, no. 2, pp. 539-548, 2015.

[15] W. Jiang, W. Xu, M. Yang et al., "Cr(VI) adsorption and reduction by humic acid coated on magnetite," Environmental Science and Technology, vol. 48, no. 14, pp. 8078-8085, 2014.

[16] S. Koesnarpadi, S. J. Santosa, D. Siswanta, and B. Rusdiarso, "Humic Acid Coated $\mathrm{Fe}_{3} \mathrm{O}_{4}$ Nanoparticle for Phenol Sorption," Indonesian Journal of Chemistry, vol. 17, no. 2, pp. 274-283, 2017.

[17] N. K. Devaraj, S. R. Elghazali, L. S. Ganapathe, A. S. M. Mukter-Uz-Zaman, and H. Y. Wong, "As(V) adsorption kinetics of humic acid-coated magnetite particles," Applied Mechanics and Materials, vol. 892, pp. 72-78, 2019.

[18] F. Aparicio, J. P. Escalada, E. de Gerónimo et al., "Carbamazepine Degradation Mediated by Light in the Presence of Humic Substances-Coated Magnetite Nanoparticles," Nanomaterials, vol. 9, no. 10, article 1379, 2019.

[19] S. J. Santosa, E. S. Kunarti, N. H. Aprilita, B. Wulandari, and D. N. Bawani, "Sorption Mechanism and Performance of Peat Soil Humin for Methylene Blue and p-Nitrophenol," Indonesian Journal of Chemistry, vol. 19, no. 1, pp. 198-210, 2018.

[20] S. Chianese, A. Fenti, P. Iovino, D. Musmarra, and S. Salvestrini, "Sorption of Organic Pollutants by Humic Acids: A Review,” Molecules, vol. 25, no. 4, p. 918, 2020.

[21] P. M. Thabede, N. D. Shooto, T. Xaba, and E. B. Naidoo, "Magnetite functionalized Nigella sativa seeds for the uptake of chromium(VI) and lead(II) ions from synthetic wastewater," Adsorption Science and Technology, vol. 2021, article 6655227, pp. 1-15, 2021.

[22] A. Hooijer, M. Silvius, H. Wösten et al., "PEAT-CO2," in Assessment of $\mathrm{CO} 2$ emissions from drained peatlands in $\mathrm{SE}$ Asia, vol. 3943, Delft Hydraulics report Q, 2006.

[23] S. E. Page and A. Hooijer, "In the line of fire: the peatlands of Southeast Asia," Philosophical Transactions of the Royal Society B: Biological Sciences, vol. 371, no. 1696, article 20150176, 2016.

[24] J. O. Rieley, R. A. J. Wüst, J. Jauhiainen et al., "Tropical peatlands: carbon stores, carbon gas emissions and contribution to climate change processes," in Peatlands and climate change, pp. 148-181, International Peat Society, 2008.
[25] A. Dohong, A. A. Aziz, and P. Dargusch, "Carbon emissions from oil palm development on deep peat soil in Central Kalimantan Indonesia," Anthropocene, vol. 22, pp. 31-39, 2018.

[26] C. Freeman, C. D. Evans, D. T. Monteith, B. Reynolds, and N. Fenner, "Export of organic carbon from peat soils," Nature, vol. 412, no. 6849, p. 785, 2001.

[27] E. T. A. Mitchard, "The tropical forest carbon cycle and climate change," Nature, vol. 559, no. 7715, article 300, pp. 527-534, 2018.

[28] K. H. Roucoux, T. R. Baker, D. del Castillo Torres et al., "Threats to intact tropical peatlands and opportunities for their conservation," Conservation Biology, vol. 31, no. 6, pp. 1283-1292, 2017.

[29] J. Wu, H. Yu, D. Wei et al., "Effects of aeration rates on the structural changes in humic substance during co-composting of digestates and chicken manure," Science of the Total Environment, vol. 658, pp. 510-520, 2019.

[30] F. Yang, S. Zhang, K. Cheng, and M. Antonietti, “A hydrothermal process to turn waste biomass into artificial fulvic and humic acids for soil remediation," Science of the Total Environment, vol. 686, pp. 1140-1151, 2019.

[31] R. Spaccini, V. Cozzolino, V. Di Meo, D. Savy, M. Drosos, and A. Piccolo, "Bioactivity of humic substances and water extracts from compost made by ligno- cellulose wastes from biorefinery," Science of the Total Environment, vol. 646, pp. 792-800, 2019.

[32] X. Guo, H. T. Liu, and S. B. Wu, "Humic substances developed during organic waste composting: formation mechanisms, structural properties, and agronomic functions," Science of the Total Environment, vol. 662, pp. 501-510, 2019.

[33] A. Piccolo, R. Spaccini, A. De Martino, F. Scognamiglio, and V. di Meo, "Soil washing with solutions of humic substances from manure compost removes heavy metal contaminants as a function of humic molecular composition," Chemosphere, vol. 225, pp. 150-156, 2019.

[34] N. S. Barot and H. K. Bagla, "Extraction of humic acid from biological matrix - dry cow dung powder," Green Chemistry Letters and Reviews, vol. 2, no. 4, pp. 217-221, 2009.

[35] M. Rastogi, M. Nandal, and L. Nain, "Additive effect of cow dung slurry and cellulolytic bacterial inoculation on humic fractions during composting of municipal solid waste," International Journal of Recycling of Organic Waste in Agriculture, vol. 8, no. 3, article 277, pp. 325-332, 2019.

[36] R. Basuki, S. J. Santosa, and B. Rusdiarso, “The novel kinetics expression of Cadmium (II) removal using green adsorbent horse dung humic acid (Hd-Ha)," in International Conference on Chemistry, Chemical Process and Engineering (IC3PE), vol. 1823, Universitas Islam Indonesia, Yogyakarta, Indonesia, 2017.

[37] B. Rusdiarso, R. Basuki, and S. J. Santosa, "Evaluation of Lagergren kinetics equation by using novel kinetics expression of sorption of $\mathrm{Zn}^{2+}$ onto horse dung humic acid (HD-HA)," Indonesian Journal of Chemistry, vol. 16, no. 3, pp. 338-346, 2016.

[38] A. Hanc, V. Enev, T. Hrebeckova, M. Klucakova, and M. Pekar, "Characterization of humic acids in a continuousfeeding vermicomposting system with horse manure," Waste Management, vol. 99, pp. 1-11, 2019.

[39] D. C. Jose, "Evaluation of organic fertilizers on selected highland vegetables," 2016. 
[40] M. L. Westendorf, C. A. Williams, S. Murphy, L. Kenny, and M. Hashemi, "Generation and management of manure from horses and other equids," Animal Manure: Production, Characteristics, Environmental Concerns, and Management, vol. 67, pp. 145-163, 2020.

[41] F. J. Stevenson, Humus Chemistry: Genesis, Composition, Reactions, John Wiley \& Sons, New York, 1994.

[42] L. Ai, F. Liao, Y. Wang et al., "Removal of methylene blue from aqueous solution with magnetite loaded multi- wall carbon nanotube: Kinetic, isotherm and mechanism analysis," Journal of Hazardous Materials, vol. 198, pp. 282-290, 2011.

[43] R. Albrecht, J. Le Petit, G. Terrom, and C. Périssol, “Comparison between UV spectroscopy and nirs to assess humification process during sewage sludge and green wastes co-composting," Bioresource Technology, vol. 102, no. 6, pp. 4495-4500, 2011.

[44] R. Zbytniewski and B. Buszewski, "Characterization of natural organic matter (NOM) derived from sewage sludge compost. Part 2: multivariate techniques in the study of compost maturation," Bioresource Technology, vol. 96, no. 4, pp. 479-484, 2005.

[45] A. Gieguzynska and others, "Studies on humic acids in eroded soils of Western Pomerania. 1. Differentiation of some chemical as well as optical properties of humic acids along the eroded slope," 1998.

[46] H. Elhajjouji, N. Fakharedine, G. Aitbaddi et al., "Treatment of olive mill waste-water by aerobic biodegradation: an analytical study using gel permeation chromatography, ultravioletvisible and Fourier transform infrared spectroscopy," Bioresource Technology, vol. 98, no. 18, pp. 3513-3520, 2007.

[47] G. Magnacca, E. Montoneri, L. Celi et al., "Novel magnetite nanoparticles coated with waste-sourced biobased substances as sustainable and renewable adsorbing materials," ACS Sustainable Chemistry and Engineering, vol. 2, no. 6, pp. 1518-1524, 2014.

[48] B. Gu, J. Schmitt, Z. Chen, L. Liang, and J. F. McCarthy, "Adsorption and desorption of natural organic matter on Iron oxide: mechanisms and models," Environmental Science and Technology, vol. 28, no. 1, pp. 38-46, 1994.

[49] E. Illés and E. Tombácz, "The effect of humic acid adsorption on $\mathrm{pH}$-dependent surface charging and aggregation of magnetite nanoparticles," Journal of Colloid and Interface Science, vol. 295, no. 1, pp. 115-123, 2006.

[50] Q. Fu, B. Hu, X. Zhou, Q. Hu, and J. Sheng, "Impact of key geochemical parameters on the attenuation of $\mathrm{Pb}$ (II) from water using a novel magnetic nanocomposite: fulvic acid-coated magnetite nanoparticles," Desalination and Water Treatment, vol. 57, no. 54, pp. 26063-26072, 2016.

[51] Z. A. AL-Othman, R. Ali, and M. Naushad, "Hexavalent chromium removal from aqueous medium by activated carbon prepared from peanut shell: adsorption kinetics, equilibrium and thermodynamic studies," Chemical Engineering Journal, vol. 184, pp. 238-247, 2012.

[52] T. Zehra, L. B. L. Lim, and N. Priyantha, "Removal behavior of peat collected from Brunei Darussalam for $\mathrm{Pb}(\mathrm{II})$ ions from aqueous solution: equilibrium isotherm, thermodynamics, kinetics and regeneration studies," Environmental Earth Sciences, vol. 74, no. 3, article 4273, pp. 2541-2551, 2015.

[53] Y. Liu, T. Li, G. Zeng, B. Zheng, W. Xu, and S. Liu, "Removal of $\mathrm{Pb}(\Pi)$ from aqueous solution by magnetic humic acid/chitosan composites," Journal of Central South University, vol. 23, no. 11, article 3344, pp. 2809-2817, 2016.
[54] E. Iskrenova-Tchoukova, A. G. Kalinichev, and R. J. Kirkpatrick, "Metal cation complexation with natural organic matter in aqueous solutions: molecular dynamics simulations and potentials of mean force," Langmuir, vol. 26, no. 20, pp. 15909-15919, 2010.

[55] J. Ma, C. Wang, W. Xi et al., "Removal of Radionuclides from Aqueous Solution by Manganese Dioxide-Based Nanomaterials and Mechanism Research: A Review," ACS ES \& $T$ Engineering, vol. 1, no. 4, pp. 685-705, 2021.

[56] X. Zhong, W. Liang, H. Wang, C. Xue, and B. Hu, "Aluminum-based metal-organic frameworks (CAU-1) highly efficient $\mathrm{UO}_{2}{ }^{2+}$ and $\mathrm{TcO}_{4}{ }^{-}$ions immobilization from aqueous solution," Journal of Hazardous Materials, vol. 407, article 124729, 2021.

[57] Z. Lin, Y. Hu, Y. Yuan, B. Hu, and B. Wang, "Comparative analysis of kinetics and mechanisms for $\mathrm{Pb}$ (II) sorption onto three kinds of microplastics," Ecotoxicology and Environmental Safety, vol. 208, article 111451, 2021.

[58] M. M. Dubinin and L. V. Radushkevich, "The equation of the characteristic curve of the activated charcoal USSR," Proceedings of the Academy of Sciences Physical Chemistry Section, vol. 55, pp. 331-337, 1947.

[59] M. I. Tempkin and V. Pyzhev, "Kinetics of ammonia synthesis on promoted iron catalyst," Acta physicochimica URSS, vol. 12, no. 1, pp. 327-356, 1940.

[60] V. J. Inglezakis and A. A. Zorpas, "Heat of adsorption, adsorption energy and activation energy in adsorption and ion exchange systems," Desalination and Water Treatment, vol. 39, no. 1-3, pp. 149-157, 2012.

[61] A. A. Edathil, I. Shittu, J. Hisham Zain, F. Banat, and M. A. Haija, "Novel magnetic coffee waste nanocomposite as effective bioadsorbent for $\mathrm{Pb}(\mathrm{II})$ removal from aqueous solutions," Journal of Environmental Chemical Engineering, vol. 6, no. 2, pp. 2390-2400, 2018.

[62] D. Mohan, P. Singh, A. Sarswat, P. H. Steele, and C. U. Pittman Jr., "Lead sorptive removal using magnetic and nonmagnetic fast pyrolysis energy cane biochars," Journal of Colloid and Interface Science, vol. 448, pp. 238-250, 2015.

[63] B. Guo, F. Deng, Y. Zhao, X. Luo, S. Luo, and C. Au, "Magnetic ion-imprinted and -SH functionalized polymer for selective removal of $\mathrm{Pb}(\mathrm{II})$ from aqueous samples," Applied Surface Science, vol. 292, pp. 438-446, 2014.

[64] S. Pap, V. Bezanovic, J. Radonic et al., "Synthesis of highlyefficient functionalized biochars from fruit industry waste biomass for the removal of chromium and lead," Journal of Molecular Liquids, vol. 268, pp. 315-325, 2018.

[65] M. Irani, M. Amjadi, and M. A. Mousavian, "Comparative study of lead sorption onto natural perlite, dolomite and diatomite," Chemical Engineering Journal, vol. 178, pp. 317-323, 2011.

[66] A. Kushwaha, R. Rani, and J. K. Patra, "Adsorption kinetics and molecular interactions of lead $[\mathrm{Pb}(\mathrm{II})]$ with natural clay and humic acid," International journal of Environmental Science and Technology, vol. 17, no. 3, article 2411, pp. 13251336, 2020.

[67] R. Chen, L. Shen, X. Wang et al., "Lead(II) and methylene blue removal using a fully biodegradable hydrogel based on starch immobilized humic acid," Chemical Engineering Journal, vol. 268, pp. 348-355, 2015.

[68] P. Bartczak, Ł. Klapiszewski, N. Karwańska et al., "Removal of nickel(II) and lead(II) ions from aqueous solution using peat 
as a low-cost adsorbent: A kinetic and equilibrium study," Arabian Journal of Chemistry, vol. 11, no. 8, pp. 1209-1222, 2018.

[69] M. Naushad, Z. A. ALOthman, M. R. Awual, M. M. Alam, and G. E. Eldesoky, "Adsorption kinetics, isotherms, and thermodynamic studies for the adsorption of $\mathrm{Pb}^{2+}$ and $\mathrm{Hg}^{2+}$ metal ions from aqueous medium using $\mathrm{Ti}(\mathrm{IV})$ iodovanadate cation exchanger," Ionics, vol. 21, no. 8, article 1401, pp. 2237-2245, 2015.

[70] M. I. Jalees, M. U. Farooq, S. Basheer, and S. Asghar, "Removal of heavy metals from drinking water using Chikni Mitti (kaolinite): isotherm and kinetics," Arabian Journal for Science and Engineering, vol. 44, no. 7, article 3722, pp. 6351-6359, 2019.

[71] M. Naushad, "Surfactant assisted nano-composite cation exchanger: development, characterization and applications for the removal of toxic $\mathrm{Pb}^{2+}$ from aqueous medium," Chemical Engineering Journal, vol. 235, pp. 100-108, 2014.

[72] R. Ren, K. Li, C. Zhang, D. Liu, and J. Sun, "Biosorption of tetradecyl benzyl dimethyl ammonium chloride on activated sludge: kinetic, thermodynamic and reaction mechanisms," Bioresource Technology, vol. 102, no. 4, pp. 3799-3804, 2011.

[73] C. Duran, D. Ozdes, A. Gundogdu, and H. B. Senturk, "Kinetics and isotherm analysis of basic dyes adsorption onto almond shell (Prunus dulcis) as a low cost adsorbent," Journal of Chemical and Engineering Data, vol. 56, no. 5, pp. 21362147, 2011.

[74] K. Vijayaraghavan, T. Padmesh, K. Palanivelu, and M. Velan, "Biosorption of nickel(II) ions onto Sargassum wightii : application of two- parameter and three-parameter isotherm models," Journal of Hazardous Materials, vol. 133, no. 1-3, pp. 304-308, 2006.

[75] P. Saha, S. Chowdhury, S. Gupta, and I. Kumar, "Insight into adsorption equilibrium, kinetics and thermodynamics of Malachite green onto clayey soil of Indian origin," Chemical Engineering Journal, vol. 165, no. 3, pp. 874-882, 2010.

[76] S. Shen, X. Liu, L. Yuan et al., "Adsorption of Pd(II) complexes from chloride solutions obtained by leaching chlorinated spent automotive catalysts on ion exchange resin Diaion WA21J," Journal of Colloid and Interface Science, vol. 345, no. 1, pp. 12-18, 2010.

[77] S. Lagergren, "Kungliga svenska vetenskapsakademiens," The Hand, vol. 24, no. 4, pp. 1-39, 1898.

[78] Y. S. Ho and G. McKay, "Sorption of dye from aqueous solution by peat," Chemical Engineering Journal, vol. 70, no. 2, pp. 115-124, 1998.

[79] R. Basuki, S. Ngatijo, J. Santosa, and B. Rusdiarso, "Comparison the new kinetics equation of Non-competitive sorption $\mathrm{cd}(\mathrm{II})$ and $\mathrm{Zn}(\mathrm{II})$ onto green sorbent horse dung humic acid (HD-HA)," Bulletin of Chemical Reaction Engineering \& Catalysis, vol. 13, no. 3, pp. 475-488, 2018.

[80] S. Agarwal and A. Rani, "Adsorption of resorcinol from aqueous solution onto $\mathrm{CTAB} / \mathrm{NaOH} /$ flyash composites: Equilibrium, kinetics and thermodynamics," Journal of Environmental Chemical Engineering, vol. 5, no. 1, pp. 526-538, 2017.

[81] A. A. Sari, M. Muryanto, E. Triwulandari et al., "Mechanism, adsorption kinetics and applications of carbonaceous adsorbents derived from black liquor sludge," Journal of the Taiwan Institute of Chemical Engineers, vol. 77, pp. 236-243, 2017.

[82] E. Gunasundari, “Adsorption isotherm, kinetics and thermodynamic analysis of $\mathrm{Cu}(\mathrm{II})$ ions onto the dried algal biomass
(Spirulina platensis)," Journal of Industrial and Engineering Chemistry, vol. 56, pp. 129-144, 2017.

[83] P. M. Stähelin, A. Valério, S. M. . A. Guelli Ulson de Souza, A. da Silva, J. A. Borges Valle, and A. A. Ulson de Souza, "Benzene and toluene removal from synthetic automotive gasoline by mono and bicomponent adsorption process," Fuel, vol. 231, pp. 45-52, 2018.

[84] A. A. A. Darwish, M. Rashad, and H. A. al-Aoh, "Methyl orange adsorption comparison on nanoparticles: isotherm, kinetics, and thermodynamic studies," Dyes and Pigments, vol. 160, pp. 563-571, 2019. 